\title{
O ARCO MAGMÁTICO DE MARA ROSA, GOIÁS: GEOQUÍMICA E GEOCRONOLOGIA E SUAS IMPLICAÇÕES REGIONAIS
}

\author{
MARIA DAS GRAÇAS VIANA*, MÁRCIO M. PIMENTEL*, MARTIN J. WHITEHOUSE**, \\ REINHARDT A. FUCK* \& NUNO MACHADO***
}

\begin{abstract}
THE MARA ROSA MAGMATIC ARC, GOIÁS: GEOCHEMICAL AND GEOCHRONOLOGICAL DATA AND THEIR REGIONAL SIGNIFICANCE The Mara Rosa volcano-sedimentary sequence consists of several NNE-trending belts of metavolcanic (metabasalts to metarhyolites) and metasedimentary rocks (micaschists, quartzites, cherts), exposed over large areas of the Tocantins Province, a Neoproterozoic (Brasiliano) orogenic region in central Brazil. The supracrustaJ belts are separated by terranes dominated by metatonalites and metadiorites and intruded by several post-orogenic granitic and dioritic bodies. This metavolcanic/metaplutonic rock association has been previously interpreted as a typical Archaean granite-greenstone terrane and, therefore, part of the sialic basement to the Brasíliano supracrustal fold belt. In this paper we present the first reliable geochronological and isotopic data for rocks of the Mara Rosa sequence and associated metaplutonic rocks. Samples of a felsic metavolcanic rock from the Posse gold mine, and of a metatonalite yielded U-Pb zircon ages of $862 \pm 8 \mathrm{Ma}$ and 856 $+13 /-7 \mathrm{Ma}$, respectively. These are interpreted as crystallization ages of the igneous protoliths. Titanite from the metavolcanic rock sample yielded a concordant recrystallization age of $632 \pm 4 \mathrm{Ma} \mathrm{Rb}$-Sr geochronological data for orthogneissic, metasedimentary and mylonitic rocks indicate the closure of $\mathrm{Rb}$-Sr isotopic system at ca. $600 \mathrm{Ma}$ after isotopic re-homogeneization. Sm-Nd isotopes for these rocks indicate primitive compositions, with $\varepsilon_{\mathrm{Nd}}(\mathrm{T})$ of +4.6 and +3.7 and TDM model ages of ca. $1.0 \mathrm{Ga}$. A syn-tectonic dioritic intrusion has an $\mathrm{U}-\mathrm{Pb}$ crystallization age of $630 \pm 6 \mathrm{Ma}$, and $\varepsilon_{\mathrm{Nd}}(\mathrm{T})$ of +1.9 and $\mathrm{T}_{\mathrm{DM}}$ of ca. $1.0 \mathrm{Ga}$. Additional Sm-Nd analyses of metasedimentary rocks and post-orogenic granites of the Mara Rosa region showed TDM ages between ca. 1.2 and 1.0 Ga. The isotopic data, combined with preliminary trace element results, suggest that the protoliths of the investigated metavolcanic and metaplutonic rocks formed at ca. $860 \mathrm{Ma}$ in an island arc system, off the coast of the São Francisco-Congo continent. Recrystallization and deformation ages of ca. 630 Ma could represent the timing of final ocean closure and continental collision.

The rock associations, structural pattern, geochronological and isotopic characteristics of the rocks from the Mara Rosa region are very similar to those of Neoproterozoic arc terrains exposed ca. $300 \mathrm{~km}$ to the southwest, in the Arenopolis area, proving the regional importance of the Neoproterozoic crustal accretion event in the central part of Brazil.
\end{abstract}

Keywords: Tocantins Province, Brasília Belt, Brasíliano Cycle, island arcs, Neoproterozoic, crustal accretion.

\begin{abstract}
RESUMO A Seqüência Vulcano-Sedimentar de Mara Rosa compreende várias faixas de direção NNE, formadas por rochas metavulcânicas (metabasaltos a metariolitos) e metassedimentares (micaxistos, quartzitos, cherts), expostas ao longo de extensas áreas da Província Tocantins. As faixas supracrustais são separadas por terrenos com metatonalitos e metadioritos, e foram intrudidas por vários corpos de granito e diorito pós-orogenéticos. Esta associação de rochas metavulcânicas/metaplutônicas foi anteriormente interpretada como um típico terreno gfsaàto-greenstone arqueano e, portanto, parte do embasamento siálico do cinturão supracrustal dobrado Brasíliano. Neste artigo são apresentados novos dados geocronológicos e isotópicos das rochas da Seqüência de Mara Rosa e metaplutônicas associadas. Amostras de uma rocha metavulcânica félsica da mina aurífera de Posse e de um metatonalito possuem idade U-Pb em zircão de $862 \pm \mathrm{Ma}$ e $856+13 /-7$ Ma respectivamente. Essas idades são interpretadas como as de cristalização dos protólitos ígneos. Titanita de uma amostra da rocha metavulcânica apresenta uma idade concordante de recristalização de $632 \pm 4$ Ma. Idades isocrônicas $\mathrm{Rb}-\mathrm{Sr}$ em ortognaisses, rochas metassedimentares e milonitos indicam o fechamento do sistema isotópico $\mathrm{Rb}-\mathrm{Sr}$ há ca. de $600 \mathrm{Ma}$ após re-homogeneização isotópica. Dados isotópicos Sm-Nd dessas rochas indicam composições primitivas, com $\varepsilon_{\mathrm{Nd}}(\mathrm{T})$ de $+4,6 \mathrm{a}+3,7$ e idades modelo TDM de cerca de 1,0 Ga. Uma intrusão sin-tectônica diorítica tem idade U-Pb de cristalizacão de $630 \pm 6 \mathrm{Ma}$ com $\varepsilon_{\mathrm{Nd}}(\mathrm{T})$ de $+1,9 \mathrm{Ga}$. e $\mathrm{T}_{\mathrm{DM}}$ de ca. 1,0 Ga. Análises adicionais Sm-Nd em rochas metassedimentares e granitos pós-orogenéticos da região de Mara Rosa mostram idades TDM entre 1,2 e 1,0 Ga. Os dados isotópicos, combinados com resultados preliminares de elementos traço, sugerem que os protólitos das rochas metavulcânicas e metaplutônicas estudadas formaram-se há cerca de $860 \mathrm{Ma}$ em um sistema de arcos de ilhas, na costa do continente São Francisco-Congo. Idades de deformação e recristalização de ca. de 630 Ma podem representar a época de fechamento final do oceano e colisão continental.

As associações litológicas, o padrão estrutural, as características geocronológicas e isotópicas das rochas da região de Mara Rosa são muito semelhantes às dos terrenos de arco expostos cerca de $300 \mathrm{Km}$ a sudoeste, na área de Arenópolis, comprovando a importância regional do evento de acreção crustal neoproterozóico na parte central do Brasil.
\end{abstract}

Palavras-chaves: Província Tocantins, Faixa Brasília, Ciclo Brasíliano, arco-de-ilhas, Neoproterozóico, acreção crustal.

INTRODUÇÃO A configuração e movimentação dos continentes e os processos tectônicos que aglutinaram e dispersaram supercontinentes durante o Neoproterozóico têm sido amplamente discutidos em publicações recentes (Bond et al 1984, Bell \& Jefferson 1987, Dalziel 1991,1992,1995,
Hoffman 1991, Moores 1991, Brito Neves \& Cordani 1991 Young 1995).

O estudo dos paleoambientes dos cinturões orogenéticos neoproterozóicos (Brasílianos e Pan-Africanos), bem como a determinação da idade e da natureza dos eventos de formação 
de rochas e de metamorfismo/deformação são essenciais para entender: (i) os processos envolvidos na formação e dispersão dos supercontinentes neoproterozóicos e (ii) as importantes mudanças ambientais e biológicas ocorridas no Neoproterozóico, as quais têm sido atribuídas a causas tectônicas maiores (Asmeron et al. 1991, Derry et al. 1992, Knoll 1992, Moores 1993).

Na porção central do Brasil está a chamada Província Tocantins (Almeida et al. 1981), representando uma importante faixa orogenética Brasíliana originada pela junção dos crátons Amazônico e do São Francisco, e possivelmente de um terceiro bloco cratônico, o Bloco Paraná, encoberto pelas rochas sedimentares da Bacia do Paraná (Figura 1). A junção dessas áreas continentais participou da aglutinação do Gondwana Ocidental (Brito Neves \& Cordani 1991), no fim do Neoproterozóico. Nos últimos anos, a incorporação de dados geocronológicos e isotópicos ao grande acervo de dados de campo auxiliaram substancialmente na elucidação do modo de evolução tectônica da Província Tocantins e, por conseguinte, do seu enquadramento nos processos geotectônicos globais do Neoproterozóico (Pimentel \& Fuck 1992, Pimentel et al. 1991a, 1991b, 1992, Ferreira Filho 1994, Suita et al 1994, Rodrigues \& Pimentel 1995). Dados isotópicos U-Pb,
Rb-Sr e Sm-Nd revelaram a existência, no oeste de Goiás, entre as cidades de Bom Jardim e Sanclerlândia (Figura 1), de terrenos que correspondem a antigos arcos de ilha de idade neoproterozóica. Datação U-Pb em zircão também indica atividade magmática riolítica/granítica sin-tectônica há cerca de $790 \mathrm{Ma}$, associada às rochas supracrustais da Faixa Brasília (Pimentel et al. 1992). Metamorfismo granulítico de idade semelhante ocorreu nos complexos máfico-ultramáficos de Niquelândia e Barro Alto (Ferreira Filho et al. 1994, Suita et al 1994). Os dados geocronológicos, isotópicos e geoquímicos recentes apontam para a ocorrência de importantes eventos magmáticos e metamórficos neoproterozóicos em várias áreas da Província Tocantins, em especial na Faixa Brasília, sugerindo que a Província evoluiu segundo um modelo ensimático.

Nesse artigo são apresentados e discutidos novos dados geocronológicos, isotópicos e geoquímicos que indicam a importância regional do evento de acreção de material manto-derivado à crosta continental na região central do Brasil, durante o Neoproterozóico. Será demonstrado que terrenos juvenis Neoproterozóicos também afloram nas porções centrais do Maciço de Goiás, e podem se estender por grandes áreas da porção norte da Província Tocantins.

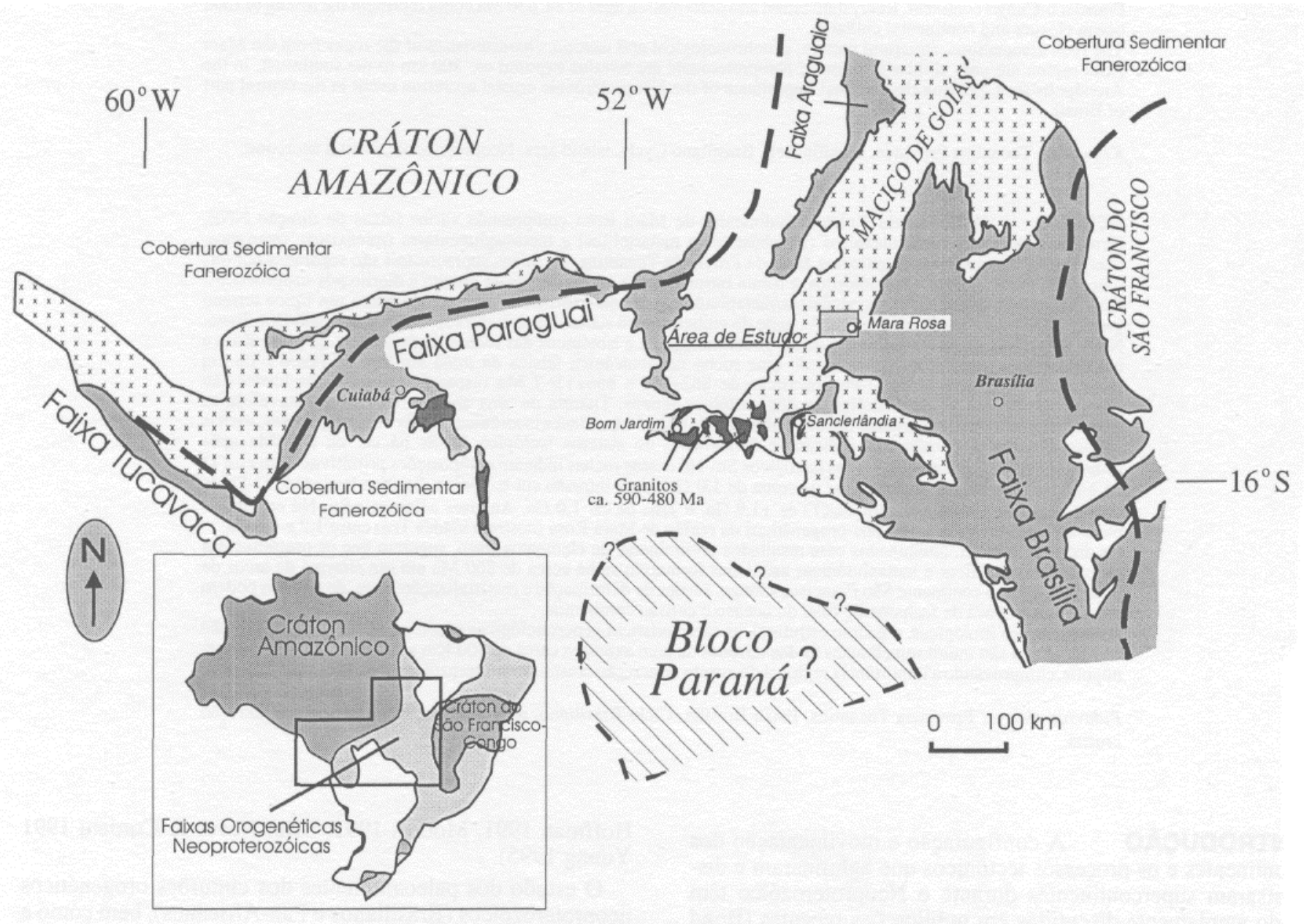

Figura l-Esboço tectônico regional da Província Tocantins, Brasil central. Figure 1 - Tectonic sketch map of the Tocantins Province, central Brazil. 
GEOLOGIA REGIONAL A área investigada localiza-se nas imediações da cidade de Mara Rosa, Goiás, na porção central da Província Tocantins (Figura 1). Essa província estrutural é uma região orogenética neoproterozóica, formada pelo encontro dos crátons do São Francisco e Amazônico e, possivelmente, de um terceiro bloco continental, o Bloco Paraná, encoberto pelas rochas sedimentares da Bacia do Paraná (Figura 1). A Província Tocantins é constituída de faixas de dobramentos conhecidas individualmente como faixas Brasília, Araguaia e Paraguai. A primeira desenvolveuse no flanco oeste do Cráton do São Francisco, e as últimas, nas bordas leste e sudeste/sul do Cráton Amazônico, respectivamente.

A Faixa Brasília é um complexo cinturão de dobras e falhas de empurrão com vergências tectônica e metamórfica em direção ao Cráton do São Francisco. Ela é constituída de diversas unidades metassedimentares interpretadas como uma seqüência de margem continental passiva. Muito embora diversos aspectos da evolução geológica da Faixa Brasília ainda estejam mal entendidos ou investigados, ela exibe muitas das feições de cadeias de montanhas modernas (Fuck et al. 1994). Exemplos são a melange ofiolítica associada aos metassedimentos do Grupo Araxá (Drake Jr. 1980, Strieder \& Nilson 1992), na porção interna da faixa, os terrenos de arco no oeste de Goiás, magmatismo félsico de caráter colisional também associado às rochas do Grupo Araxá, bem como o desenvolvimento de extensas lâminas de cavalgamento e nappes indicando encurtamento horizontal substancial e transporte tectônico em direção ao Cráton do São Francisco.

Entre as Faixas Araguaia e Paraguai, no oeste, e a Faixa Brasília, a leste, situam-se os terrenos cristalinos do Maciço de Goiás (Fig. 1). Ele compreende uma complexa associação de terrenos granito-gnáissicos de idades variadas (Fuck et al. 1987). Áreas arqueanas de típicos terrenos granito-greenstone são conhecidas na parte central do maciço, na região compreendida entre Crixás e Hidrolina (Fig. 2) e mais aa sul, nas vizinhanças da cidade de Goiás. A presença dessas associações arqueanas, bem como de outras unidades de idade paleoproterozóica, levaram alguns autores a sugerir idade arqueana/paleoproterozoica'para todo o Maciço de Goiás (e.g. Danni et al. 1982, Hasui et al. 1994). No entanto, dados geocronológicos recentes demonstram que associações do tipo arco-de-ilha de idade neoproterozóica constituem extensas áreas da porção sudoeste/sul do maciço, entre as cidades de Bom Jardim e Sanclerlândia (Fig. 1) (Pimentel et al. 1991a, Pimentel \& Fuck 1992). Nessa região, datações radiométricas de diversas seqüências vulcano-sedimentares previamente tratadas como greenstone belts arqueanos ou paleoproterozóicos (Bernasconi 1983, lanhez et al 1984) revelaram idades entre ca. 930 e $640 \mathrm{Ma}$ (dados Rb-Sr e U-Pb; Pimentel et al. 1991a, Pimentel \& Fuck 1993, Rodrigues \& Pimentel 1995). Os valores de $\varepsilon_{\mathrm{Nd}}(\mathrm{T})$ das rochas metavulcânicas e metaplutônicas são positivos, entre ca. $+6,9$ e $+0,2$ e as razões iniciais ${ }^{87} \mathrm{Sr} /{ }^{86} \mathrm{Sr}$ são inferiores a 0,705 , indicando o caráter juvenil dos magmas originais. A extensão desses terrenos de arco neoproterozóico, em direção a norte do Maciço de Goiás, foi anteriormente sugerida, mas a falta de dados geocronológicos não permitiu uma conclusão definitiva.

Este estudo apresenta e discute dados geocronológicos, isotópicos e geoquímicos novos de unidades litológicas expostas na região de Mara Rosa, parte central do Maciço de Goiás e a norte dos terrenos arqueanos da região de CrixásHidrolina (Fig. 2).

\section{GEOLOGIA DA REGIÃO DE MARA ROSA}

$\mathrm{Na}$

região entre as cidades de Mara Rosa, Chapada e Porangatu, norte de Goiás (Fig. 2), projetos de mapeamento regional e estudos de reconhecimento realizados durante a última década (Machado 1981, Ribeiro Filho 1981, Lacerda 1986), identifi- caram importantes exposições de seqüências vulcano-sedimentares, dispostas em faixas de direção NNE e separadas por gnaisses de composição tonalítica a granodiorítica.

As principais características das unidades litológicas das vizinhanças de Mara Rosa foram apresentadas por Arantes et ai. (1991). As rochas supracrustais são dominantemente metavulcânicas e distribuem-se em três faixas de direção NNE, designadas de Leste, Central e Oeste, e separadas por terrenos de ortognaisses (Fig. 2). As rochas supracrustais, designadas coletivamente de Seqüência vulcano-sedimentar de Mara Rosa, consistem de metabasaltos, meta-piroclásticas de composição intermediária, rochas metavulcânicas félsicas, metagrauvacas finas, granada-mica xistos, metachert, formações ferríferas, quartzitos e rochas meta-ultramáfícas, todas metamorfizadas em fácies xisto verde a anfibolito. Pequenos depósitos auríferos ocorrem nas faixas central e leste, como exemplificam os de Posse e Zacarias (Arantes et al. 1991). De acordo com Arantes et al (1991), a Faixa Leste é composta de quatro unidades litoestratigráficas, que da base para o topo, compreendem:

Unidade Amaro Leite - metagrauvacas com intercalações de metatufos máficos;

Unidade Araras - metatufos máficos a intermediários, com intercalações de metagrauvacas, metavulcânicas félsicas e metachert;

Unidade Posse - metatufos félsicos, lapilli-tufos e biotitaplagioclásio gnaisses;

Unidade Carambolas - metatufos e derrames vulcânicos máficos com intercalações de metavulcânicas félsicas.

A Faixa Central é composta predominantemente por rochas metavulcânicas máficas, formações ferríferas manganesíferas e metassedimentos carbonosos, subordinadamente rochas ultramáficas.

A Faixa Oeste é constituída de rochas metavulcânicas máficas sotopostas a metavulcânicas félsicas e a um pacote espesso de metassedimentos (granada-muscovita-biotita xistos, freqüentemente feldspáticos). Rochas metaultramáficas dessa faixa foram interpretadas por Arantes et al (1991) como derivadas de derrames, muito embora não tenham sido encontradas evidências texturais e estruturais para tanto.

Os gnaisses dioríticos a tonalíticos situados entre as faixas de supracrustais são petrografícamente homogêneos, mas com predominância dos últimos. Os gnaisses possuem granulação média a grossa e localmente apresentam texturas e estruturas plutônicas reliquiares (Viana 1995). Aos terrenos gnáissicos freqüentemente se associam pequenos corpos circulares e lenticulares de metagabro e hornblendito grossos, interpretados como termos máficos do magmatismo que originou os protólitos dos metatonalitos. Na região de Chapada, a sudoeste de Mara Rosa, Kuyumjian (1989) descreve gnaisses e metagabros semelhantes e os interpreta como rochas manto-derivadas, de afinidade calcialcalina, similares a granitóides de arcos magmáticos. As relações de contato e de idade entre os ortognaisses e as supracrustais são ainda obscuras devido à falta de exposições, tanto em Chapada quanto em Mara Rosa. Entretanto, Arantes et al (1991) descrevem enclaves de rochas supracrustais nos metatonalitos, indicando a natureza intrusiva do protólito.

Gnaisses e supracrustais da região foram intrudidos por grandes corpos pós-tectônicos de diorito e de granito (Fig. 2). Os primeiros concentram-se na porção norte na área da Figura 2 e são constituídos por dioritos e quartzo dioritos. Os últimos são representados por biotita granitos e leucogranitos a duas micas, subordinadamente granodioritos.

Estas unidades estendem-se para o sul, até a falha do Rio dos Bois (Fig. 2), uma falha inversa que as separa dos terrenos arqueanos de Crixás-Hidrolina. Essa falha se prolonga para nordeste, separando os terrenos vulcano-sedimentares de Mara Rosa, a oeste, das rochas metassedimentares do Grupo 


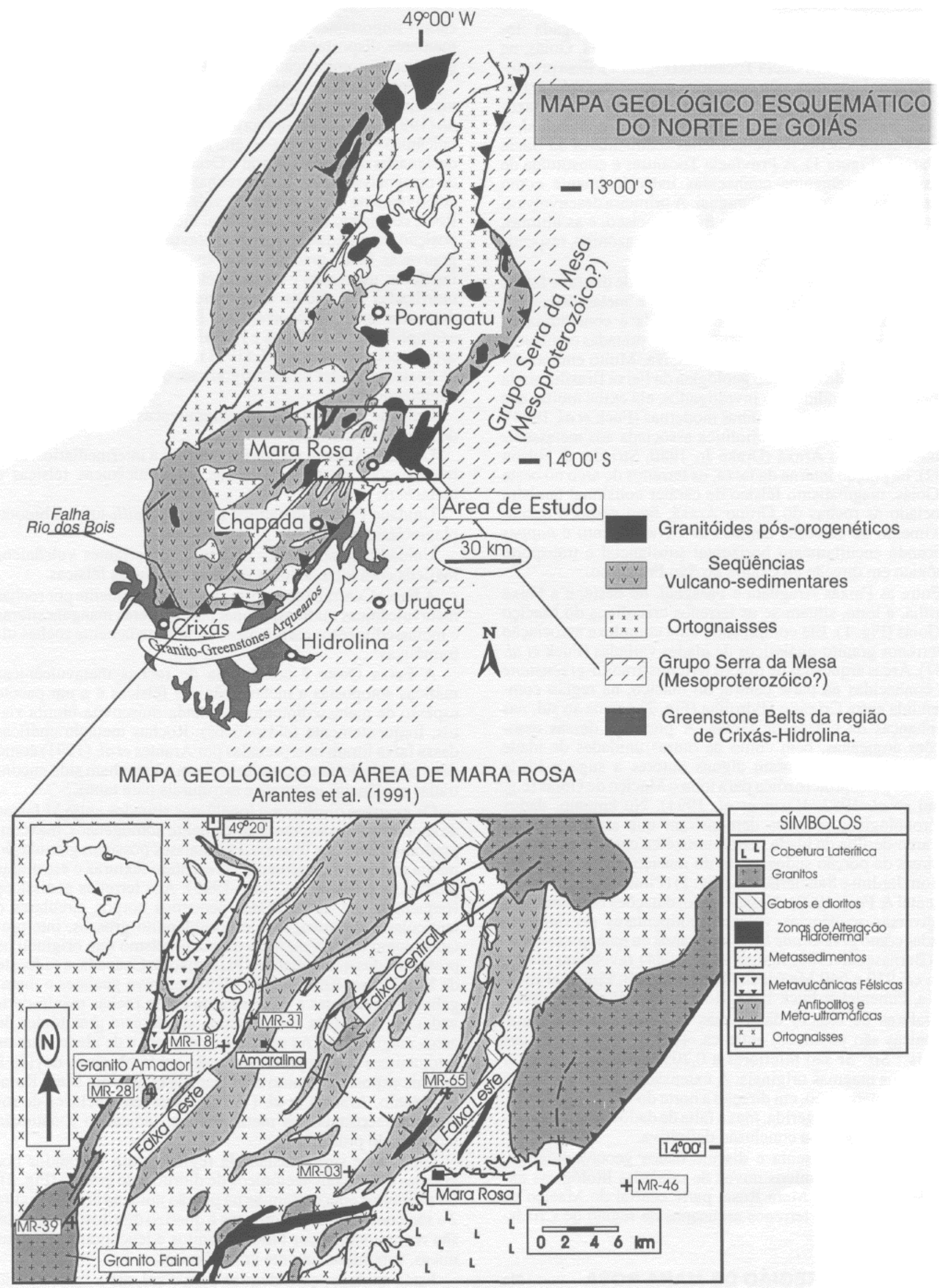

Figura 2 - Mapa geológico da região de Mara Rosa, norte de Goiás.

Figure 2 - Geological map of the Mara Rosa region, northern Goiás. 
Serra da Mesa (Mesoproterozóico?) e seu embasamento siálico, a leste.

Os dados geocronológicos disponíveis na literatura para a região de Chapada-Mara Rosa-Porangatu restringem-se a algumas idades $\mathrm{Rb}-\mathrm{Sr}$ e $\mathrm{K}-\mathrm{Ar}$, resumidas na Tabela 1 . Os dados K-Ar da região são de Hasui \& Almeida (1970) e registram idades entre 470 e 730 Ma para micas e anfibólios. A maior parte das idades isocrônicas $\mathrm{Rb}-\mathrm{Sr}$ têm sido interpretadas como marcadoras de eventos de rehomogeneização isotópica durante o Brasíliano, de modo análogo ao observado por Reis Neto (1983) na região de Cavalcante, a leste de Mara Rosa. Isócronas minerais obtidas por Richardson et al (1988) em biotita xistos da Seqüência de Mara Rosa, na região de Chapada, forneceram idades de ca. 524 e $532 \mathrm{Ma}$, interpretadas como representantes da época do metamorfismo. Uma isócrona mineral de um diorito indeformado forneceu uma idade de ca. $534 \mathrm{Ma}$ (Richardson et al 1988). As razões iniciais ${ }^{87} \mathrm{Sr} /{ }^{86} \mathrm{Sr}$, geralmente baixas $(0,705)$, sugerem residência crustal limitada dos protólitos das rochas metavulcânicas e dos dioritos da região de Chapada (Richardson et al 1988). Entretanto, há sugestões de que as unidades da região de Chapada-Mara Rosa eqüivalem aos terrenos granite-greenstone de 2,6-3,0 Ga, expostos a sul da falha do Rio dos Bois (Machado 1981, Hasui et al. 1994).

PROCEDIMENTOS ANALÍTICOS Todos os procedimentos de datação U-Pb foram realizados no GEOTOP, Université du Quebèc au Montréal, Canadá. Os concentrados de minerais pesados foram obtidos por meio de mesa do tipo Wilfley. As frações de pesados foram processadas por peneiramento, separação magnética em separador isodinâmico FRANTZ e em bromofórmio e iodeto de metileno.

As frações de zircão foram selecionadas a partir das frações menos magnéticas, por separação manual em álcool etílico filtrado, e os cristais são homogêneos em tamanho, cor e forma. Os cristais de titanita também foram escolhidos manualmente em frações magnéticas de 1 a 1,7A. Para reduzir a discordância, utilizou-se uma combinação de (i) separação manual dos grãos mais transparentes, menos alterados e sem fraturas ou inclusões, e (ii) abrasão dos grãos ao ar, usando pirita como polidor (Krogh 1982).

Para remover grãos remanescentes de pirita após a abrasão, as frações de zircão foram lavadas a quente por duas vezes em HNOs (4N), seguido de repetidos enxagües com água destilada e acetona.

As frações de zircão foram, então, pesadas e dissolvidas em uma mistura de ácidos fluorídrico e nítrico, na proporção 15:1, usando bombas de teflon tipo Parr, a $220^{\circ} \mathrm{C}$. As de titanita foram dissolvidas a temperaturas mais baixas, usando cápsulas fechadas Savillex ${ }^{\mathrm{TM}}$ em uma placa quente. A dissolução e extração química de $\mathrm{U}$ e $\mathrm{Pb}$ seguiram os procedimentos gerais descritos por Krogh (1973) e a separação desses elementos foi feita por cromatografia de troca aniônica, em microcolunas feitas em teflon.

$\mathrm{Pb}$ e $\mathrm{U}$ foram depositados conjuntamente, na forma de fosfato, com sílica-gel, em filamentos de Re degaseificados. As medidas isotópicas foram feitas em um espectrômetro de massa VG-Sector, no GEOTOP. Os dados isotópicos foram corrigidos para valores de fracionamento de $0.1 \%$ por unidade de massa atômica. Os "brancos" totais de $\mathrm{U}$ e $\mathrm{Pb}$ no laboratório, quando foram feitas as análises, eram de ca. de 2 e $10-20 \mathrm{pg}$, respectivamente. Os valores das constantes de decaimento usados e a composição isotópica de $U$ são aqueles apresentados por Steiger \& Jãger (1977). As correções para o $\mathrm{Pb}$ comum foram feitas usando o modelo de evolução isotópica de Stacey \& Kramers (1975).

A obtenção do sal de $\mathrm{Sr}$, a partir das amostras de rocha, foi feita no Laboratório de Geocronologia da Universidade de Brasília, a partir de cerca de $200 \mathrm{mg}$ de pó de amostra* pesados
Tabela l - Dados geocronológicos existentes para as unidades precambrianas da região de Chapada-Mara Rosa-Porangatu.

Table 1 - Geochronological data for precambrian rock units of the Chapada-Mara Rosa-Porangatu region.

\begin{tabular}{|c|c|c|}
\hline $\begin{array}{c}\text { Unidade } \\
\text { Geológica/Rocha/ } \\
\text { Mineral }\end{array}$ & Método & Idade (Ma) \\
\hline $\begin{array}{l}\text { Anfibólio } \\
\text { (anfibolito da } \\
\text { Seqüência de Mara } \\
\text { Rosa) }{ }^{1}\end{array}$ & K-Ar & $730 \pm 37$ \\
\hline $\begin{array}{l}\text { Biotita } \\
\text { (ortognaisse) }\end{array}$ & K-Ar & $\begin{array}{l}517 \pm 16 \\
533 \pm 16 \\
\end{array}$ \\
\hline $\begin{array}{l}\text { Muscovita } \\
\text { (pegmatito) }^{\mathrm{i}}\end{array}$ & $\overline{\mathbf{K}-\mathbf{A}_{\mathbf{I}}}$ & $478 \pm 15$ \\
\hline $\begin{array}{l}\text { Metavulcânica } \\
\text { félsica (regiäo đe } \\
\text { Chapada) }\end{array}$ & $\begin{array}{c}\text { Isócrona } \mathrm{Rb}-\mathrm{Sr} \text { rocha } \\
\text { total }\end{array}$ & $\begin{array}{c}561 \pm 9 \\
(\text { r.i. }=0.7041)\end{array}$ \\
\hline $\begin{array}{l}\text { Biotita xisto } \\
\text { (regiāo de } \\
\text { Chapada) }^{2}\end{array}$ & $\begin{array}{c}\text { Is6cronas Rb-Sr em } \\
\text { minerais }\end{array}$ & $\begin{array}{l}524 \pm 2 \\
532 \pm 1\end{array}$ \\
\hline $\begin{array}{l}\text { Diorito intrusivo } \\
\text { (regiăo de } \\
\text { Chapada) }\end{array}$ & $\begin{array}{l}\text { Is6crona Rb-Sr em } \\
\text { minerais }\end{array}$ & $534 \pm \overline{16}$ \\
\hline $\begin{array}{l}\text { Granito-gnaisse } \\
\text { (regiāo de } \\
\text { Poranganu) }\end{array}$ & $\begin{array}{l}\text { Isocrona de } \\
\text { referencia Rb-Sr } \\
\text { rocha-total }\end{array}$ & $\begin{array}{c}589 \pm 61 \\
(\mathrm{r} . \mathrm{i}=0.705)\end{array}$ \\
\hline
\end{tabular}

1- Hasui \& Almeida (1970). 2- Richardson et al, (1988).

3-Tassinari et al. (1981).

em béqueres de teflon. A dissolução da amostra foi feita com $4 \mathrm{ml}$ de HF concentrado e $1 \mathrm{ml}$ de HNOs. A solução foi evaporada em chapa quente e o resíduo dissolvido em $6 \mathrm{ml}$ de HNOs, seguido de evaporação até a completa secagem, retomada com $6 \mathrm{ml}$ de $\mathrm{HCl} 6 \mathrm{M}$ e nova evaporação. O resíduo foi, então, dissolvido em $3 \mathrm{ml}$ de $\mathrm{HC} 1(2,5 \mathrm{M})$, seguido de centrifugação.

Uma alíquota de $1 \mathrm{ml}$ de solução centrifugada foi colocada em coluna de troca catiônica (AG 50W X8, 200-400 mesh) equilibrada com $\mathrm{HC} 12,5 \mathrm{M}$, seguido de lavagem da coluna com $37 \mathrm{ml}$ de $\mathrm{HCl}$ 2,5M, descartados. São passados pela coluna, então, $15 \mathrm{ml}$ do mesmo ácido, que são coletados em béqueres de teflon. Essa solução é levada à secagem, quando, então, se obtém o sal de Sr.

As análises espectrométricas foram feitas no Laboratório de Geocronologia da USP. As amostras são colocadas em filamentos de Ta, com $\mathrm{H} 2 \mathrm{O}$ e $\mathrm{HsPO} 4$, sendo as análises feitas em um espectrômetro de massa do tipo VG 354. Os erros 2a são menores que $0,02 \%$ nas razões ${ }^{87} \mathrm{Sr} /{ }^{86} \mathrm{Sr}$. As razões ${ }^{87} \mathrm{Rb} /{ }^{86} \mathrm{Sr}$ foram obtidas a partir de determinações de $\mathrm{Rb}$ e $\mathrm{Sr}$ efetuadas por Fluorescência de Raios-X, também no Laboratório de Geocronologia da USP. Erros menores que 2\% são estimados para essas determinações.

A amostragem dos diversos litotipos obedeceu a cogeneticidade das amostras, o que foi assegurado pela coleta em um mesmo afloramento, desde que com dimensões suficientes para uma amostragem significativa. Tal procedimento, apesar de garantir essa premissa, gera uma variação muito pequena na razão ${ }^{87} \mathrm{Rb} /{ }^{86} \mathrm{Sr}$ no lote coletado. Assim, o espalhamento 
dos pontos na isócrona é pequeno, o que aumenta o erro das idades $\mathrm{Rb}$-Sr. Essa é a principal razão para os altos valores dos erros nas idades, encontrados nesse estudo. Todos esses erros são indicados dentro do intervalo de confiança de $95 \%$.

As análises isotópicas de $\mathrm{Sm}$ e $\mathrm{Nd}$ foram realizadas inteiramente no Laboratório de Geocronologia da Universidade de Oxford, Inglaterra.

A determinação das concentrações de $\mathrm{Sm}$ e $\mathrm{Nd}$ foi feita por diluição isotópica, usando spikes de ${ }^{149} \mathrm{Sm}$ e ${ }^{150} \mathrm{Nd}$. O Sm é separado do Nd após a obtenção dos ETR a partir do pó da rocha, usando cromatografia de troca iônica.

Em bombas de teflon foram pesados $150 \mathrm{mg}$ de pó de rocha e $200 \mathrm{mg}$ de uma solução do spike misto. A dissolução foi feita em bomba vedada, a $150^{\circ} \mathrm{C}$, usando cerca de $5 \mathrm{ml}$ de $\mathrm{HF}$ $48 \%$ e $100 \mu \mathrm{l}$ de $\mathrm{HNO}_{3} 16 \mathrm{M}$, para dissolver as fases silicáticas. A solução foi evaporada até secar e submetida a um segundo ataque, após o qual foi aquecida a $150^{\circ} \mathrm{C}$ por algumas horas, para a completa dissolução das fases resistentes. Uma segunda evaporação gerou um resíduo ao qual foram adicionados $3 \mathrm{ml}$ de $\mathrm{HC} 16 \mathrm{~N}$ e 2 a $3 \mathrm{ml}$ de $\mathrm{HsBO} 4$, saturado em $\mathrm{HC} 1$. A solução foi aquecida a $150^{\circ} \mathrm{C}$ e posteriormente evaporada até secar. $\mathrm{O}$ resíduo sofreu ataque com 2 a 2,5 $\mathrm{ml}$ de $\mathrm{HC} 13 \mathrm{M}$, formando uma solução que foi então centrifugada.

Os ETR foram separados em colunas de troca catiônica, com resina AG 50 X12, 200-400 mesh. Nas colunas, equilibradas com HC1 3M, foram depositados $2 \mathrm{ml}$ da soluçãoamostra. As colunas foram lavadas com 1,3 ml de $\mathrm{HC} 13 \mathrm{M}$. São passados então $20 \mathrm{ml}$ de $\mathrm{HC} 1$, coletando-se em béqueres de teflon apenas os $10 \mathrm{ml}$ finais, nos quais encontra-se a fração de ETR. A solução é evaporada até secar.

As frações de $\mathrm{Sm}$ e Nd foram obtidas a partir deste resíduo, por adição de $1 \mathrm{OOul}$ de $\mathrm{HC1}(0,15 \mathrm{M})$. São transferidos $0,1 \mathrm{ml}$ de amostra para colunas de ácido di-(2-etilexil)fosfórico (HDEHP), misturado a pó de teflon (PTFE). A eluição das frações de $\mathrm{Nd}$ e Sm é feita com HC1 0,3M. A fração de Nd é obtida com a passagem de 3,5 $\mathrm{ml}$ desse ácido. Depois disso, mais $3,5 \mathrm{ml}$ de $\mathrm{HCl}$ são passados, porém desprezados. São coletados $9 \mathrm{ml}$ de $\mathrm{HC1}$, para a obtenção da fração de Sm.
As amostras de $\mathrm{Sm}$ e Nd foram depositadas nos filamentos laterais de um arranjo triplo de filamentos (o central de Re e os laterais de Ta), usando HNOs $1 \mathrm{M}$. As análises, que tiveram precisão de $0.025 \%$ (2d) nos valores de $\mathrm{Sm}$ e $\mathrm{Nd}$, foram feitas usando um espectrômetro de massa VG Isomass 54E, inteiramente automático. A razão ${ }^{143} \mathrm{Nd} /{ }^{144} \mathrm{Nd}$ apresentou um erro $2 \mathrm{a} \pm 0.000020$. Essa razão foi normalizada com ${ }^{146} \mathrm{Nd} /{ }^{144} \mathrm{Nd}$ $=0,7219$.

As análises químicas foram todas feitas no Laboratório de Geoquímica da Universidade de Brasília, por espectrometria de plasma (ICP).

\section{CARACTERÍSTICAS GEOOUÍMICAS DAS RO-} CHAS METAPLUTÔNICAS DA REGIÃO DE MARA ROSA Os resultados das análises químicas de elementos maiores e traço em amostras de ortognaisses da região de Mara Rosa constam da Tabela 2. Essas rochas apresentam um amplo espectro de variação de $\mathrm{SiO}_{2}(52 \%$ a $69 \%)$, cobrindo o espectro diorito-granodiorito-granito), mas com predominância de tonalito (Fig. 3a). Estas rochas são dominantemente metaluminosas (Fig. 3b), com razão molecular A/CNK (AhOs/ $(\mathrm{CaO}+\mathrm{Na} 2 \mathrm{O}+\mathrm{K} 2 \mathrm{O}))$ entre 0,76 e 1,1 .

Conteúdos elevados de $\mathrm{CaO}(4,8 \%$ a $8,6 \%)$ são característicos dessas rochas, e de acordo com os critérios de Peacock (1931), apresentam um padrão de fracionamento que as classificam como pertencentes à série cálcica, o que normalmente caracteriza rochas primitivas, manto-derivadas. $\mathrm{O}$ índice alcali-cálcio (ALI) é de 64. O diagrama log $\left(\mathrm{CaO} / \mathrm{Na}_{2} \mathrm{O}+\mathrm{K}_{2} \mathrm{O}\right)$ vs. $\mathrm{SiO}_{2}$ (Fig. 3c) mostra que estas rochas possuem um caráter geoquímico "primitivo". As razões $\mathrm{CaO} / \mathrm{Na}_{2} \mathrm{O}+\mathrm{K}_{2} \mathrm{O}$ desses ortognaisses são, em geral, mais elevadas que as de andesitos calci-alcalinos modernos das suítes vulcano-plutônicas dos arcos magmáticos da região circum-pacífica. Nessas suítes, as rochas cálcicas ocorrem predominantemente nos sistemas de arco-de-ilhas imaturos, intraoceânicos (Brown 1892).

Os conteúdos de elementos maiores e alguns traço dos ortognaisses de Mara Rosa são similares aos de granitóides do

Tabela 2 A-Composição química dos gnaisses tonalíticos de Mara Rosa.

Table 2A - Chemical composition of the Mara Rosa tonalitic gneisses.

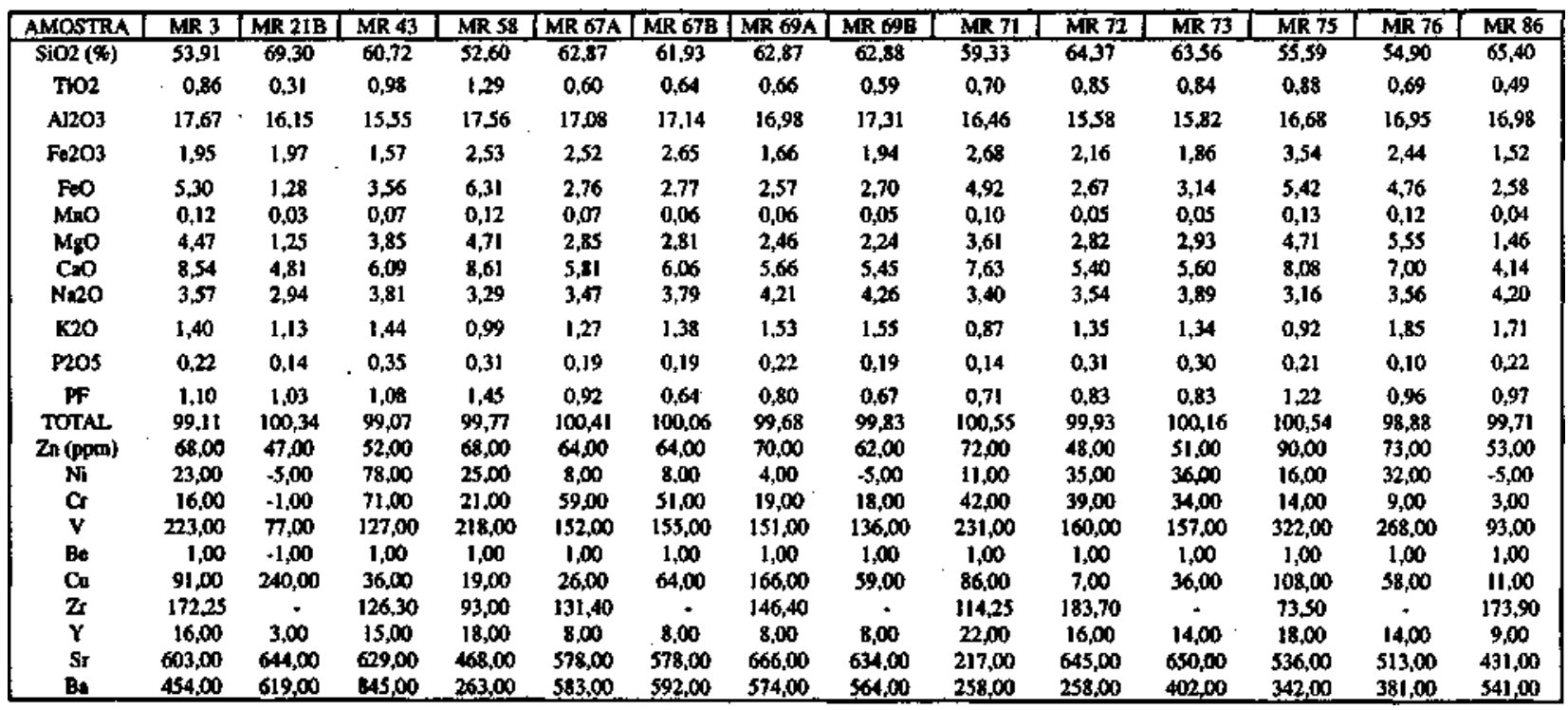


Tabela 2B - Composição química dos gnaisses tonalíticos de Mara Rosa.

Table 2B - Chemical composition of the Mara Rosa tonalitic gneisses.

\begin{tabular}{|c|r|r|r|}
\hline Amostra & MR 3 & MR 43 & MR 58 \\
\hline La & 10,380 & 26,470 & 16,740 \\
Ce & 24,720 & 48,500 & 33,810 \\
Nd & 10,850 & 18,200 & 17,650 \\
Sm & 2,729 & 4,453 & 4,136 \\
Eu & 0,871 & 1,182 & 1,004 \\
Gd & 2,566 & 3,646 & 3,596 \\
Dy & 2,647 & 2,838 & 3,536 \\
Ho & 0,519 & 0,528 & 0,745 \\
Er & 1,348 & 1,230 & 1,950 \\
Yb & 1,252 & 1,038 & 1,630 \\
Lu & 0,143 & 0,111 & 0,258 \\
\hline
\end{tabular}

tipo $\mathrm{M}$, que reúne as rochas graníticas primitivas, ricas em $\mathrm{CaO}$, manto-derivadas, características de arcos-de-ilha intraoceânicos (White 1979, Pitcher 1983, Chappell 1984). As baixas concentrações de $\mathrm{Rb}, \mathrm{Nb}, \mathrm{Ti}, \mathrm{Y}, \mathrm{Zr}$ e ETR, bem como o leve enriquecimento em elementos LIL (large ion lithophile), comparado com elementos tais como $\mathrm{Y}$, Ti e $\mathrm{Yb}$ (Fig. $3 \mathrm{~d}$ e $3 \mathrm{e}$ ) são compatíveis com as observadas em magmas intermediários a ácidos, calci-alcalinos, de ambiente de arco vulcânico.

A razão LILE/HFSE dessas rochas é similar tanto à das de arcos vulcânicos continentais, do tipo Andes, quanto imaturos, intraoceânicos.

Os gnaisses estudados apresentam baixos a moderados conteúdos de elementos terras-rara $(Z E T R=58-108 \mathrm{ppm})$. Os padrões de ETR normalizados ao condrito estão na Figura $3 f$. Há um leve fracionamento das terras-raras em relação a uma provável fonte mantélica condrítica, sendo baixas as razões ETRL/ETRP ((La/Lu)N = 7,5 a 24,7). As anomalias de Eu são discretas e as concentrações de ETRP baixas. Segundo Cullers \& Graf (1984), tonalitos com essas características requerem pouco ou nenhum plagioclásio residual na fonte do magma original, o que é compatível com uma fonte mantélica.

A amostra MR-18 é de rocha metassedimentar (muscovitabiotita xisto feldspático) da Faixa de Oeste. Essa rocha apresenta padrão ETR muito semelhante ao dos ortognaisses (Fig. $3 \mathrm{f}$ ), sugerindo que os sedimentos originais podem provir da erosão do próprio arco-de-ilhas.

O comportamento dos elementos maiores e traço dos ortognaisses de Mara Rosa é semelhantes ao dos metatonalitos de arco da região de Chapada, estudadas por Kuyumjian (1989) e petrografica e geoquimicamente aos ortognaisses tonalíticos a granodioríticos da região de Piranhas e Sanclerlândia, oeste de Goiás, estudados por Pimentel \& Fuck (1987a, 1987b, 1992) e Pimentel (1990). Essas semelhanças permitem inferir que os protólitos das rochas de Mara Rosa e do oeste de Goiás formaram-se em ambientes geotectônicos e condições petrogenéticas idênticas.

\section{RESULTADOS ISOTÓPICOS}

Método U-Pb ORTOGNAISSE (AMOSTRA MR-3) Três frações de zircão do gnaisse, após abrasão, foram analisadas (Frações MR-3.1, MR-3.2, MR-3.3, Tab. 3). Os cristais de zircão são incolores, de boa qualidade, com poucas fraturas ou inclusões, prismáticos curtos, bem formados e de tamanho médio de $200 \mu \mathrm{m}$.
Relações do tipo núcleo-sobrecrescimento não ocorrem nas populações investigadas. O conteúdo de U varia entre 90 e 176 ppm e o $\mathrm{Pb}$ comum total é relativamente baixo (12 a 30 Pg)-

A fração MR 3.1 é constituída de um único cristal e foi a que forneceu a análise mais concordante $(0,3 \%$ de discordância), com uma idade ${ }^{207} \mathrm{~Pb} /{ }^{206} \mathrm{~Pb}$ de $857 \mathrm{Ma}$. No diagrama da concórdia (Fig. 4a), o intercepto superior da discórdia, construída com os três pontos analíticos, indica uma idade de 856 +13/-7 Ma, considerada como indicadora da época de cristalização do protólito. A idade de intercepto inferior, de ca. de 287 Ma não possui significado geológico e provavelmente representa uma perda recente de $\mathrm{Pb}$.

METAVULCÂNICA FÉLSICA (AMOSTRA MR-65) Três frações de zircão e uma de titanita da amostra de rocha metavulcânica félsica da Mina de Posse foram investigadas. Os cristais de zircão dessa rocha são pequenos (100 um), incolores e prismáticos curtos. As três frações foram abradadas, sendo que as análises resultantes são concordantes. As idades ${ }^{206} \mathrm{~Pb} /{ }^{238} \mathrm{U}$ situam-se entre 861 e $862 \mathrm{Ma}$ (Fig. 4b) e são interpretadas como próximas da idade de cristalização do protólito ígneo. Essas idades foram as que apresentaram os menores erros e as menores dispersões. O erro de $\pm 8 \mathrm{Ma}$ foi estimado considerando apenas o tamanho das elipses de erro analítico. A datação do metamorfismo da fácies xisto verde alto a anfibolito nessas rochas empregou cristais de titanita, a qual é marrom escura e apresenta conteúdo de U relativamente elevado (220 ppm). O resultado obtido é concordante e gerou uma idade de $632 \pm 4$ Ma (Fig. $4 b$ ).

Esses resultados U-Pb sugerem que a rocha vulcânica original se cristalizou há cerca de 862 Ma e foi recristalizada pela última vez há ca. de 632 Ma durante o Brasíliano.

A idade da titanita é relevante com relação à época de mineralização de Au. Segundo Arantes et al. (1991), as feições texturais do minério de $\mathrm{Au}$ da Mina de Posse indicam que a mineralização ocorreu após a última fase de recristalização das rochas encaixantes. Assim, a idade de 632 Ma pode ser interpretada como o limite superior da idade da mineralização, indicando que esta possivelmente ocorreu durante os últimos estágios de deformação/recristalização do ciclo Brasíliano.

DIORITO SUBVULCÂNICO (AMOSTRA MR-31B) A datação desse corpo é relevante, uma vez que as informações de campo sugerem que sua colocação se deu sin-tectonicamente ao principal evento de deformação das rochas supracrustais encaixantes.

Três frações de zircão do diorito foram separadas. Os cristais são prismáticos longos (c:l = 5:1), característicos de corpos subvulcânicos. As análises geraram um padrão complexo no diagrama da concórdia (Fig. 4c). A fração MR 31.5, no entanto, é concordante, indicando uma idade de $630 \pm 3$ $\mathrm{Ma}$, considerada a melhor estimativa da idade de cristalização desta intrusão e da deformação das rochas encaixantes. O resultado é coerente com o obtido em titanita da rocha da Mina de Posse, sugerindo que o principal evento de deformação das rochas de Mara Rosa ocorreu há ca. de $630 \mathrm{Ma}$. As idades ${ }^{206} \mathrm{~Pb} /{ }^{238} \mathrm{U}$ situam-se entre 630 e $634 \mathrm{Ma}$.

Os resultados analíticos das frações MR 31.3 e 31.4 são, respectivamente, $7,3 \%$ e $8,0 \%$ discordantes e plotam à direita da análise concordante. Isso sugere a presença de um componente herdado, de idade indeterminada, muito embora não tenham sido observadas relações do tipo núcleo-sobrecrescimento. A pequena discordância pode também ter resultado de problemas de correção do $\mathrm{Pb}$ comum, pois as razões ${ }^{206} \mathrm{~Pb} /{ }^{204} \mathrm{~Pb}$ são pequenas e inferiores a 600 .

GRANITO PAU DE MEL (AMOSTRA MR-46) Na porção sudeste da área investigada, uma falha inversa (Falha Rio dos 

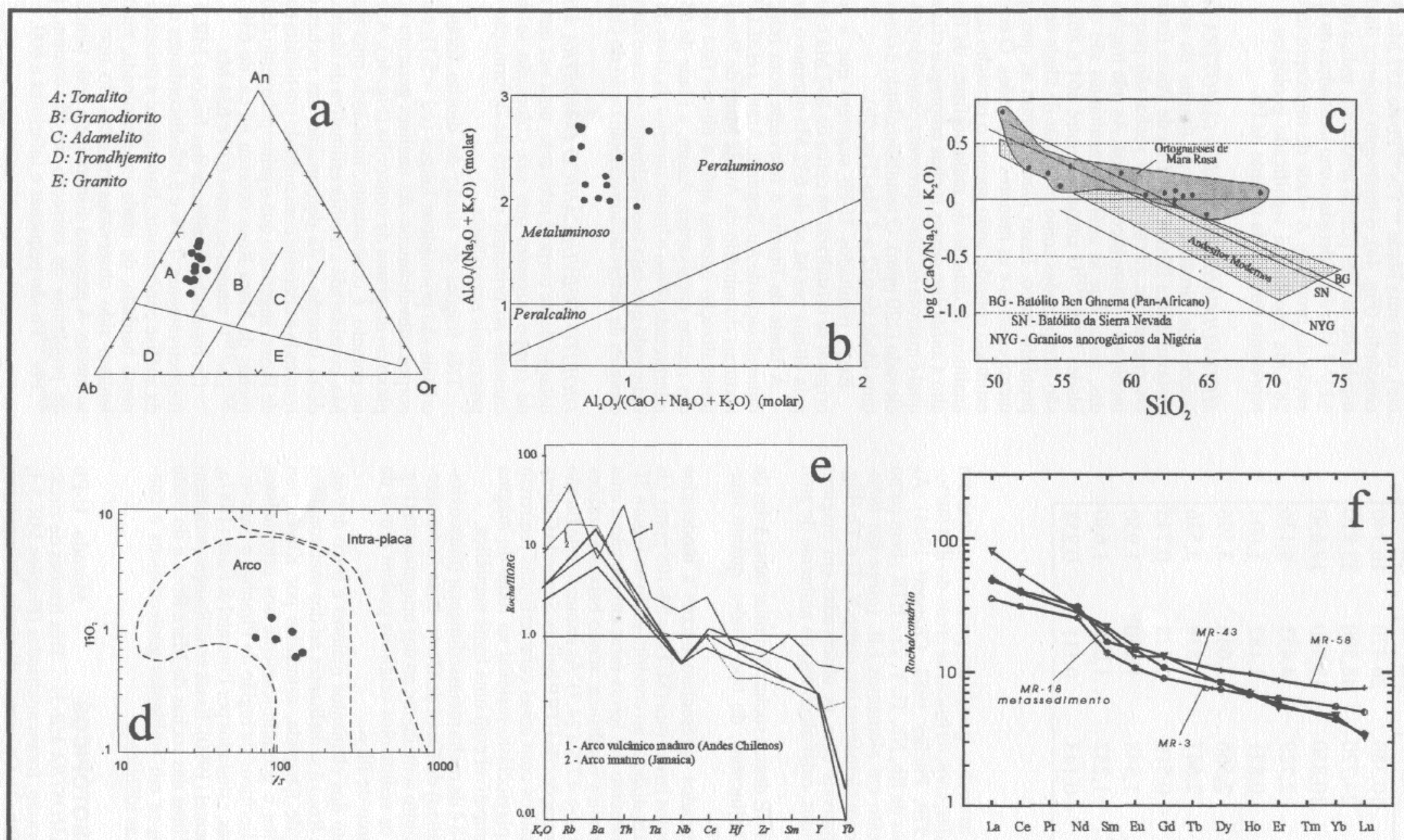

La Ce Pr Nd Sin Ea Gd Tb Dy Ho Er Tm Yb La

Figura 3 - Características químicas dos ortognaisses de Mara Rosa.

Figure 3 - Chemical characteristics of the Mara Rosa orthogneisses. 
Tabela 3 - Resultados isotópicos U-Pb.

Table $3-\mathrm{U}-\mathrm{Pb}$ isotopic results

\begin{tabular}{|c|c|c|c|c|c|c|c|c|c|c|c|c|}
\hline Amostra* & $\begin{array}{l}\text { Peso } \\
\text { (mg) }\end{array}$ & $\begin{array}{c}\mathrm{U} \\
(\mathrm{ppm})\end{array}$ & $\begin{array}{c}\mathrm{Pb} \\
(\mathrm{ppm})\end{array}$ & $\begin{array}{c}\mathrm{Pb} \\
\text { Comum } \\
(\mathrm{pg})\end{array}$ & $\begin{array}{c}207 \mathrm{~Pb} / 204 \\
\mathrm{~Pb}\end{array}$ & $\begin{array}{c}206 \mathrm{~Pb} / 238 \\
\mathrm{U} \\
( \pm 1 \mathrm{~s})\end{array}$ & $\begin{array}{c}207 \mathrm{~Pb} / 235 \\
\mathrm{U} \\
( \pm 1 \mathrm{~s})\end{array}$ & $\begin{array}{c}207 \mathrm{~Pb} / 206 \mathrm{P} \\
\mathrm{b} \\
( \pm 1 \mathrm{~s})\end{array}$ & t1 & & & 13 \\
\hline MR-3.1 z & 5 & 176 & 28.2 & 13 & 607 & $0.1417 \pm 2$ & $1.321 \pm 4$ & $0.06762 \pm 14$ & 854 & \multicolumn{2}{|r|}{855} & 857 \\
\hline MR-3.2 z & 45 & 90 & 12.9 & 12 & 2773 & $0.1362 \pm 2$ & $1.264 \pm 3$ & $0.06732 \pm 05$ & & 823 & 830 & 848 \\
\hline MR $-3.3 \mathrm{z}$ & 23 & 144 & 20.5 & 30 & 1003 & $0.1407 \pm 2$ & $1.310 \pm 3$ & $0.06756 \pm 11$ & & 848 & 850 & 855 \\
\hline MR-65.1 t & 502 & 220 & 30.3 & 1140 & 642 & $0.1030 \pm 3$ & $0.865 \pm 3$ & $0.06088 \pm 7$ & & 632 & 633 & 635 \\
\hline MR-65.2 & 18 & 50 & 8.2 & 26 & 340 & $0.1430 \pm 4$ & $1.344 \pm 6$ & $0.06816 \pm 26$ & & 862 & 865 & 873 \\
\hline MR-65.3 & 25 & 299 & 47.1 & 32 & 2537 & $0.1429 \pm 3$ & $1.340 \pm 5$ & $0.06805 \pm 21$ & & 861 & 863 & 870 \\
\hline MR-65.4 & 20 & 292 & 63.0 & 386 & 153 & $0.1431 \pm 5$ & $1.342 \pm 6$ & $0.06800 \pm 26$ & & 862 & 864 & 869 \\
\hline MR-31.3 & 25 & 72 & 8.9 & 26 & 471 & $0.1030 \pm 3$ & $0.884 \pm 5$ & $0.06228 \pm 33$ & & 632 & 643 & 684 \\
\hline MR-31.4 & 19 & 121 & 15.3 & 26 & 591 & $0.1034 \pm 3$ & $0.887 \pm 6$ & $0.06223 \pm 32$ & & 634 & 645 & 682 \\
\hline MR-31.5 & 52 & 117 & 14.6 & 33 & 1291 & $0.1027 \pm 2$ & $0.861 \pm 2$ & $0.06083 \pm 7$ & & 630 & 631 & 633 \\
\hline MR-46.1 & 20 & 108 & 46.7 & 41 & 1311 & $0.3915 \pm 5$ & $7.327 \pm 14$ & $0.13574 \pm 10$ & & 2130 & 2152 & 2173 \\
\hline MR-46.2 & 9 & 399 & 134.0 & 16 & 4543 & $0.3162 \pm 5$ & $5.834 \pm 10$ & $0.13381 \pm 8$ & & 1771 & 1951 & 2148 \\
\hline MR-46.3 & 75 & 164 & 68.0 & 53 & 5420 & $0.3765 \pm 7$ & $7.065 \pm 15$ & $0.13609 \pm 6$ & & 2060 & 2120 & 2178 \\
\hline
\end{tabular}

* - z são zircões e t são titanitas
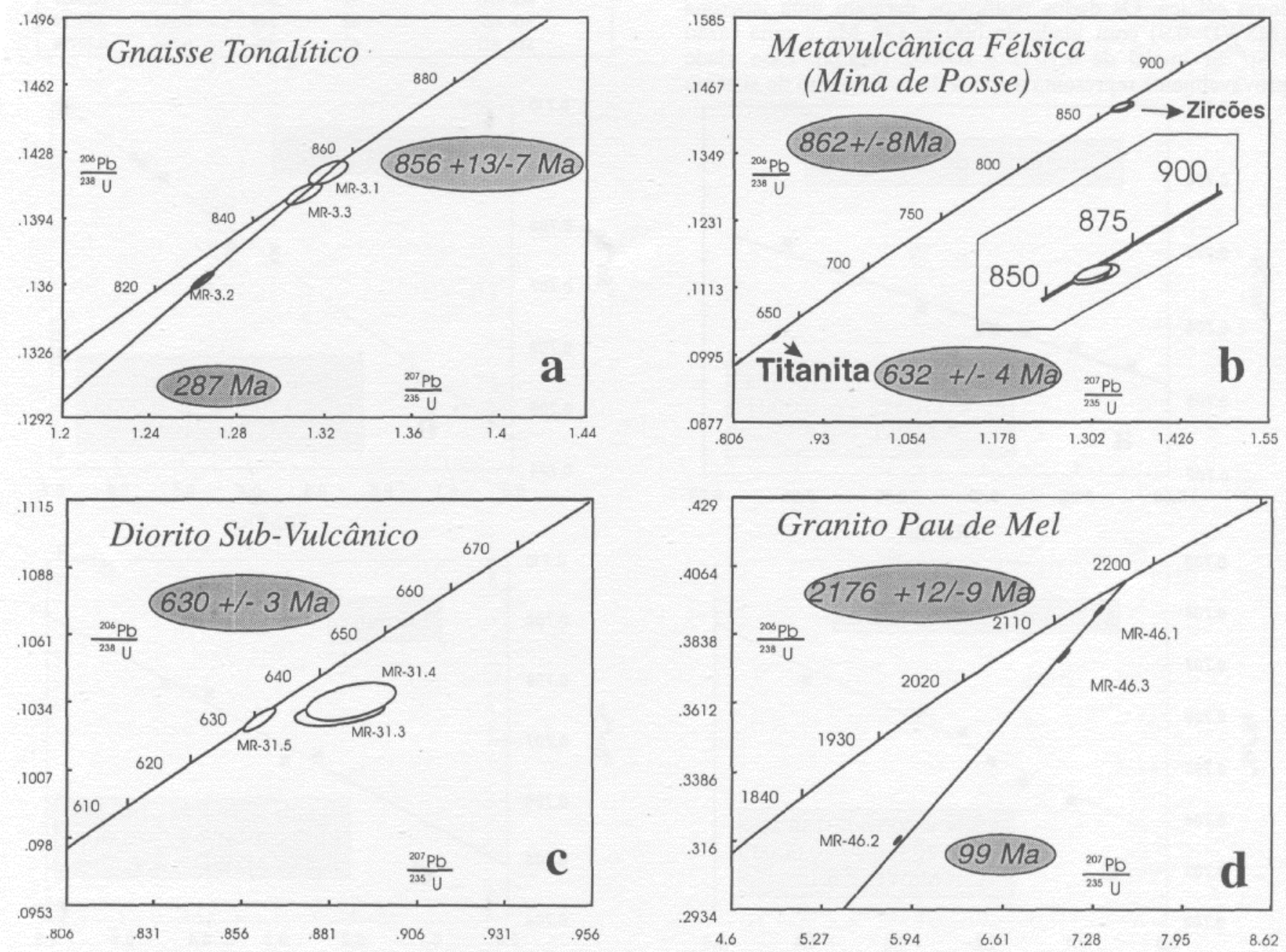

Figura 4 - Diagrama concórdia para as unidades geológicas da região de Mara Rosa.

Figure 4 - Concórdia diagrams for the geological units of the Mara Rosa region. 
Bois) separa os terrenos metavulcânicos/ metassedimentares de Mara Rosa, a oeste, dos terrenos gnáissicos sotopostos ao Grupo Serra da Mesa, a leste. De um granito bastante deformado (MR 46), denominado Granito Pau de Mel, exposto em meio aos gnaisses, analisou-se três frações de zircão. A rocha possui duas populações de zircão. Uma consiste de cristais pequenos $(=100 \mu \mathrm{m})$, prismáticos, fraturados e com inclusões, e outra de cristais maiores $(>200 \mu \mathrm{m})$, bem formados e sem inclusões. A fração MR 46.2 é constituída por cristais de zircão do primeiro tipo e as frações MR 46.1 e MR 46.3, por cristais do segundo. Os dados gerados foram bastante discordantes (Tab. 3). A melhor reta que une os três pontos indica que o granito tem uma idade de $2176+12 /-9$ Ma (Fig. 4d), a qual sugere que a falha de empurrão é um importante limite tectônico, pois separa terrenos de idades distintas. A idade de intercepto inferior de ca. de 99 Ma não tem significado geológico e resulta principalmente da perda recente de $\mathrm{Pb}$, provavelmente por intemperismo.

Método Rb-Sr ORTOGNAISSE TONALÍTICO (AMOS$T R A M R-3)$ Sete amostras de rocha total de ortognaisses tonalíticos expostos entre as faixas de leste e central foram analisadas pelo método $\mathrm{Rb}-\mathrm{Sr}$ e os resultados analíticos constam da Tabela 4. As amostras apresentam baixas razões ${ }^{87} \mathrm{Rb} /{ }^{86} \mathrm{Sr}(0,02$ a 0,20$)$, o que é consistente com a suamineralogia cálcica. Os dados isotópicos geraram uma isócrona (MSWD=0,9) com idade de $600 \pm 136 \mathrm{Ma}$ e uma razão ${ }^{87} \mathrm{Sr} /{ }^{86} \mathrm{Sr}$ inicial de $0,7032 \pm 0,0002$ (FigSa). Essa idade provavelmente representa a época do fechamento do sistema
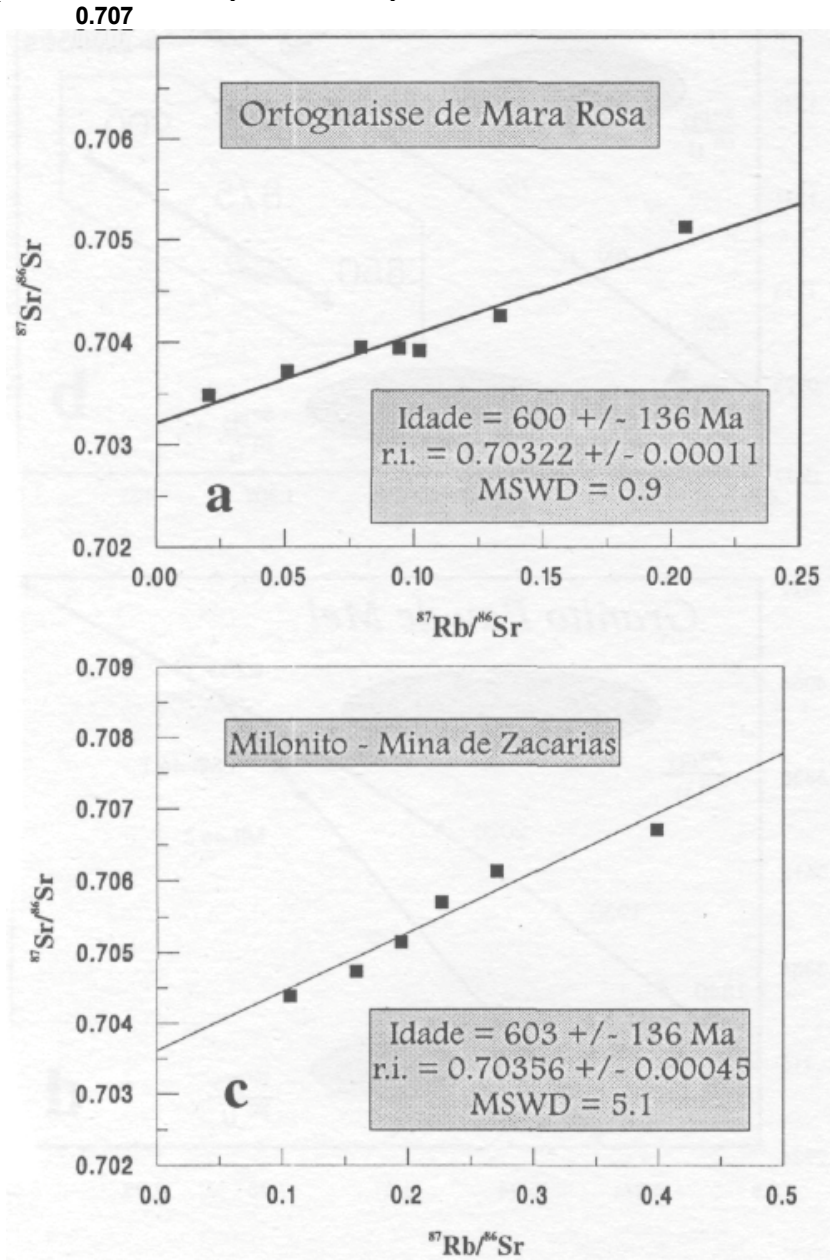

Tabela 4 - Resultados isotópicos $\mathrm{Rb}-\mathrm{Sr}$ Table 4 - Rb-Sr isotopic results.

\begin{tabular}{|c|c|c|c|c|}
\hline Amostra & $\mathrm{Rb}(\mathrm{ppm})$ & $\mathrm{Sr}(\mathrm{ppm})$ & ${ }^{87} \mathrm{Rb} /{ }^{86} \mathrm{Sr}$ & ${ }^{87} \mathrm{Sr} /{ }^{86} \mathrm{Sr}$ \\
\hline Ortognaisse & 22 & 676 & 0,094 & 0,70394 \\
MR 3A & 5 & 712 & 0,020 & 0,70349 \\
MR 3F & 18 & 657 & 0,079 & 0,70395 \\
MR 3G & 25 & 715 & 0,101 & 0,70389 \\
MR 3I & 12 & 685 & 0,050 & 0,70371 \\
MR 3L & 30 & 654 & 0,132 & 0,70425 \\
MR 3Q & 48 & 676 & 0,205 & 0,70512 \\
MR 3R & & & & \\
Metassedimento & 42 & 338 & 0,359 & 0,70759 \\
MR 18C & 49 & 253 & 0,560 & 0,70902 \\
MR 18E & 51 & 257 & 0,574 & 0,70914 \\
MR 18F & 50 & 342 & 0,422 & 0,70762 \\
MR 18J & 40 & 219 & 0,528 & 0,70880 \\
MR 18H & & & & \\
Milonito - Mina Zacarias & 17 & 254 & 0,193 & 0,70515 \\
MR 66C & 41 & 298 & 0,398 & 0,70663 \\
MR 66E & 42 & 539 & 0,225 & 0,70580 \\
MR 66G & 15 & 409 & 0,106 & 0,70439 \\
MR 66I & 47 & 504 & 0,269 & 0,70629 \\
MR 66J & 24 & 436 & 0,159 & 0,70468 \\
MR 66K & & & & \\
Diorito Pós-Tectônico & 31 & 363 & 0,247 & 0,70684 \\
MR 42B & 34 & 343 & 0,286 & 0,70657 \\
MR 42D & 48 & 313 & 0,443 & 0,70794 \\
MR 42F & 42 & 314 & 0,386 & 0,70778 \\
MR 42I & & & & \\
\hline
\end{tabular}
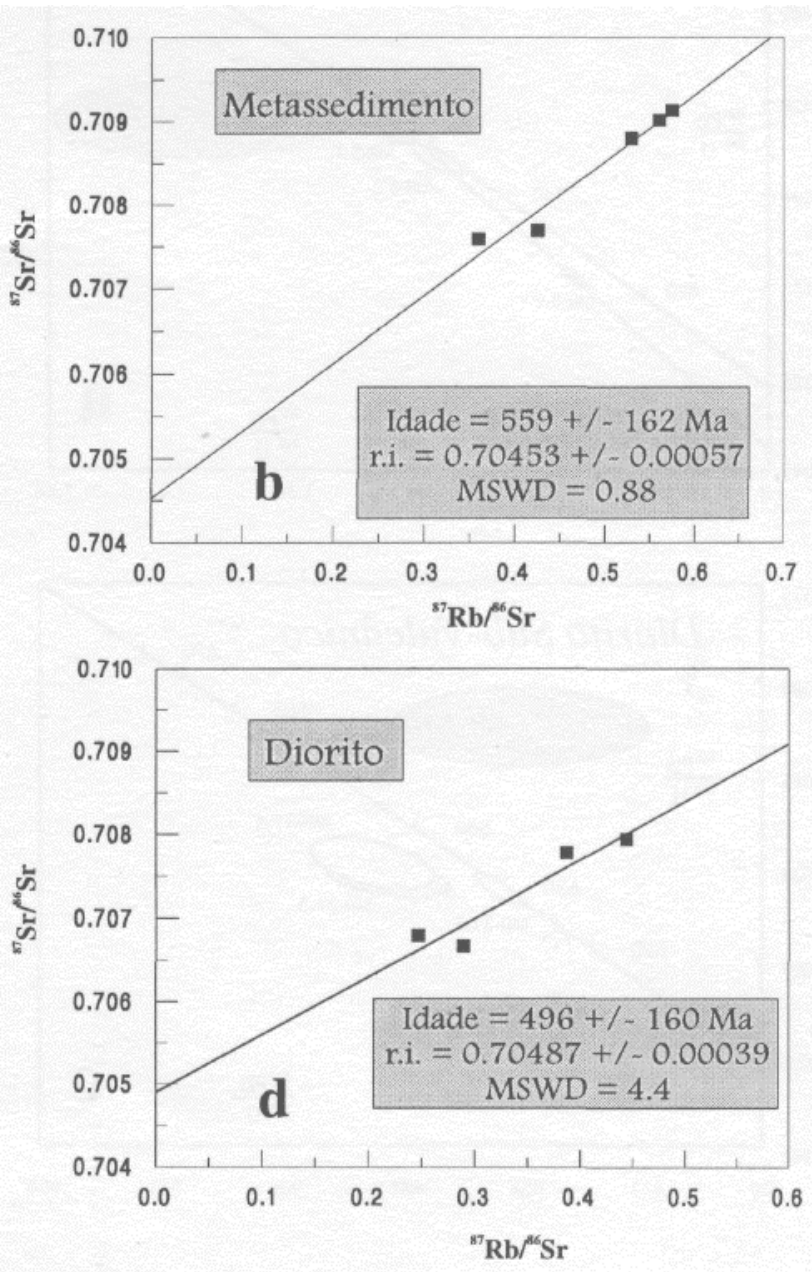

Figura 5 - Isócronas $\mathrm{Rb}$-Sr rocha-total.

Figure 5 - Whole-rock $\mathrm{Rb}-\mathrm{Sr}$ isochrons. 
isotópico $\mathrm{Rb}$ - $\mathrm{Sr}$ após o evento metamórfico de ca. 630Ma, evidenciadas pelas idades $\mathrm{U}-\mathrm{Pb}$ discutidas anteriormente. $\mathrm{O}$ baixo valor da razão ${ }^{87} \mathrm{Sr} /{ }^{86} \mathrm{Sr}$ inicial é compatível com uma curta resistência crustal.

ROCHA METASSEDIMENTAR (AMOSTRA MR-18) A análise isotopica $\mathrm{Rb}$-Sr de uma amostra de muscovita-biotita xisto feldspático da Faixa Oeste definiu uma isócrona alinhada de 5 pontos, com MSWD de 0,88 (Fig. 5 b). A idade obtida foi de $559 \pm 161 \mathrm{Ma}$, com razão inicial ${ }^{87} \mathrm{Sr} /{ }^{86} \mathrm{Sr}$ de $0,7045 \pm$ 0,0011 , um pouco mais elevada que a dos gnaisses, mas suficientemente menor para sugerir curto tempo de residência crustal. $\mathrm{O}$ grande erro na idade reflete o intervalo restrito de variação dos valores ${ }^{87} \mathrm{Rb} /{ }^{86} \mathrm{Sr}, 0,36$ a 0,58 (Tab. 4). Esta idade é interpretada como uma estimativa da época de fechamento do sistema isotópico $\mathrm{Rb}-\mathrm{Sr}$, após o metarnorfismo.

MILONITO DA MINA DE ZACARIAS (AMOSTRA MR-66) A rocha da mina de Au-Ag-Ba de Zacarias é um milonito fino, cujo protólito é difícil de ser identificado, devido ao intenso cisalhamento e recristalização. Este milonito foi datado pelo método Rb-Sr (Tab. 4), resultando em uma idade de $603 \pm 135$ Ma, com razão inicial ${ }^{87} \mathrm{Sr} /{ }^{86} \mathrm{Sr}$ de $0,7035 \pm 0,0004$ (Fig. 5c), intepretada como indicadora da época de re-homogeneização metamórfica. O grande erro da idade resulta do pequeno espalhamento dos pontos da isócrona, devido à pequena variação das razões ${ }^{87} \mathrm{Rb} /{ }^{86} \mathrm{Sr}$.

DIORITO PÓS-TECTÔNICO (AMOSTRA MR-42) Amostras de um diorito pós-tectônico da Faixa Oeste foram analisadas pelo método $\mathrm{Rb}$-Sr (Tab. 4). A razão inicial de 0,7048 $\pm 0,0007$ foi obtida a partir da isócrona de rocha total, a qual forneceu idade de $496 \pm 160 \mathrm{Ma}$ (Fig. $5 \mathrm{~d}$ ), coerente com o caráter intrusivo pós-orogenético desse corpo. O erro associado a essa idade é, novamente, resultante do pequeno espalhamento dos pontos no diagrama isocrônico.

Método Sm-Nd Amostras de rocha total de seis unidades litológicas da região de Mara Rosa foram analisadas pelo método Sm-Nd. Os resultados analíticos constam da Tabela 5. $\mathrm{O}$ ortognaisse tonalítico (amostra MR 3) tem ${ }^{143} \mathrm{Nd} /{ }^{144} \mathrm{Nd}$ atual de 0,512551 e apresentou uma idade modelo (TDM) de 1001 Ma.. Essa idade é cerca de $150 \mathrm{Ma}$ mais velha que a obtida pelo método U-Pb. O $£ \mathrm{Nd}(\mathrm{T})(\mathrm{T}=856 \mathrm{Ma})$ é positivo, $+4,6$, e indica o caráter primitivo do magma original. As características isotópicas gerais de $\mathrm{Nd}$ desse gnaisse são similares às dos gnaisses de Arenópolis, Matrinxã e Sanclerlândia. Segundo Pimentel \& Fuck (1992), os protólitos calci-alcalinos dessas rochas devem representar crosta continental nova, de idade neoprpterozóica. A interpretação é, portanto, extensiva aos ortògnaisses de Mara Rosa.

A amostra MR-31, do diorito, tem uma idade modelo de 1017 Mae $\varepsilon_{\mathrm{Nd}}(\mathrm{T})(\mathrm{T}=632 \mathrm{Ma})$ positivo, de $+2,1$. Resultados semelhantes foram obtidos para a rocha da mina de Posse (MR-65), a qual apresenta $6 \mathrm{Nd}(\mathrm{T})+3,7$, e idade modelo (TDM) de $1033 \mathrm{Ma}$,

Os valores positivos de $\varepsilon_{\mathrm{Nd}} \mathrm{CO}$ indicam que os magmas originais dessas rochas possuem um caráter "primitivo", com a participação de um componente mantélico empobrecido.

Uma amostra do metassedimento da Faixa Oeste (MR-18) também foi analisada para identificar uma possível presença de rochas mais antigas (Arqueanas/Paleoproterozóicas) nas áreas fonte dos sedimentos originais. A composição isotopica $\mathrm{Sm}-\mathrm{Nd}$ dessa rocha indica uma idade modelo jovem $(\mathrm{ToM}=$ $1,2 \mathrm{Ga}$ ), que representa o limite superior da deposição dos sedimentos. Admitindo que esses foram depositados, mais provavelmente, entre 0,7 e $1,0 \mathrm{Ga}$, a composição isotopica inicial de $\mathrm{Nd}$ resultaria em valores positivos de $\varepsilon_{\mathrm{Nd}}(\mathrm{T})$, entre ca. $+0,8$ e $+3,4$, apontando o caráter primitivo da(s) área(s) fonte. Isso sugere que eles representam sedimentos imaturos derivados da erosão de material neoproterozóico juvenil, ou seja do próprio arco magmático, com pequena ou nenhuma contribuição de material siálico mais antigo. Essa interpretação é compatível com a baixa razão ${ }^{87} \mathrm{Sr} /{ }^{86} \mathrm{Sr}$ inicial dessas rochas e com o padrão de ETR, semelhante ao dos ortognaisses tonalíticos de Mara Rosa (Fig. 3f).

Dois corpos de leucogranitos, freqüentemente a duas micas, intrudiram sin-tectonicamente os metassedimentos da Faixa Oeste. Estes denominam-se Granito Faina, situado na porção sudoeste da área estudada, e Granito Amador, exposto na porção central da Faixa Oeste (Fig. 2).

Uríia amostra do Granito Amador (MR 28) apresenta razão atual de ${ }^{143} \mathrm{Nd} /{ }^{144} \mathrm{Nd}=0,51216$. A razão ${ }^{147} \mathrm{Sm} /{ }^{144} \mathrm{Nd}$ é relativamente baixa $(0,103)$. A idade modelo deste granito é de $1209 \mathrm{Ma}$. Para o cálculo do $\varepsilon_{\mathrm{Nd}}(\mathrm{T})$ foi usada a aproximação $\mathrm{T}=600 \mathrm{Ma}$, pois esse corpo apresenta evidências de alojamento tardi a pós-orogenético e as idades U-Pb caracterizam esse evento como ocorrido há cerca de $600 \mathrm{Ma} . \mathrm{O} \varepsilon_{\mathrm{Nd}}$ obtido é negativo $(-2,1)$ indicando" que o granito formou-se a partir de uma fonte mais enriquecida em elementos LIL que as unidades geológicas descritas acima.

A amostra dó granito Faina (MR-39) tem composição isotópicaatual de $\mathrm{Nd}$ semelhante à do granito Amador, com

$\mathrm{Nd} / \wedge^{\wedge}$ íd igual a 0,512391. A sua idade modelo calculada é de $1,0 \mathrm{Ga}$ com $\varepsilon_{\mathrm{Nd}}(\mathrm{T})$ em $600 \mathrm{Ma}$ igual a $+1,5$. Esses resultados indicam quê o magma granítico original desses corpos não incorporou quantidades significativas de crosta

\begin{tabular}{|c|c|c|c|c|c|c|c|}
\hline AMOSTRA & Sm(ppm) & $\mathrm{Nd}(\mathrm{ppm})$ & ${ }^{147} \mathrm{Sm} /{ }^{144} \mathrm{Nd}$ & ${ }^{143} \mathrm{Nd} /{ }^{144} \mathrm{Nd}( \pm 2 \sigma)^{*}$ & $\varepsilon_{\mathrm{o}}$ & $\mathrm{T}_{\mathrm{DM}}(\mathrm{Ga})$ & $\varepsilon(\mathrm{T})$ \\
\hline MR-3 & 3.30 & 14.35 & 0.1390 & $0.512551 \pm 21$ & -1.7 & 1.0 & +4.6 \\
MR-28 & 3.17 & 18.61 & 0.1030 & $0.512160 \pm 19$ & -9.3 & 1.2 & $-2.1^{1}$ \\
MR-31 & 7.28 & 35.27 & 0.1248 & $0.512448 \pm 36$ & -3.7 & 1.0 & +1.9 \\
MR-65 & 6.46 & 35.39 & 0.1104 & $0.512341 \pm 20$ & -5.8 & 1.0 & +3.7 \\
MR-18 & 3.56 & 16.53 & 0.1301 & $0.512374 \pm 20$ & -5.2 & 1.2 & $+2.0^{2}$ \\
MR-39 & 6.42 & 33.98 & 0.1143 & $0.512391 \pm 27$ & -3.6 & 1.0 & $+1.5^{1}$ \\
\hline
\end{tabular}

* as incertezas indicadas se referem aos dois últimos dígilos da razăo isolópica 
continental mais antiga que as próprias encaixantes. Assim, material semelhante aos metassedimentos da Faixa Oeste da seqüência de Mara Rosa são, provavelmente, os componentes mais importantes na fonte desses magmas graníticos. Por outro lado, as características isotópicas de $\mathrm{Nd}$ desses granitos em muito se assemelham às dos granitos Rio Caiapó e Serra do Iran, do oeste de Goiás (Pimentel 1990).

\section{IMPLICACÕES TECTÔNICAS REGIONAIS}

As

composições isotópicas e geoquímicas das rochas metavulcânicas, metassedimentares e ortognaisses da região de Mara Rosa indicam que seus protólitos formaram-se durante o Neoproterozóico em um sistema de $\operatorname{arco}(\mathrm{s})$ magmático(s). Magmas juvenis cálcicos a calci-alcalinos originaram as intrusões tonalíticas e rochas vulcânicas dacítico-riolíticas entre ca. 856-862 Ma. Suas composições isotópicas de Nd sugerem que derivaram de fontes mantélicas empobrecidas. Combinados com dados de elementos maiores e traço, esses resultados sugerem que os magmas originais se formaram em ambiente de arco-de-ilhas primitivo, intraoceânico.

As idades U-Pb de titanita das rochas da Mina de Posse e do diorito sin-tectônico mostram que o último importante evento metamórfico/deformacional na área, responsável pelo desenvolvimento das extensas zonas de cisalhamento de direção NNE, ocorreu há ca. $630 \mathrm{Ma}$. Essa idade é aqui interpretada como a melhor estimativa para a época do fechamento final do oceano e colisão continental.

A composição isotópica de $\mathrm{Nd}$ da amostra de rocha metassedimentar da Faixa Oeste mostra que é improvável a presença de grandes proporções de crosta continental antiga (arqueana/paleoproterozóica) nas áreas-fonte. Isto sugere que os sedimentos originais eram imaturos e derivaram do próprio arco.

Dois granitos pós-tectônicos possuem composição isotópica de Nd compatível com fonte magmática crustal, isotopicamente similares às rochas de arco. $\mathrm{O}$ caráter peraluminoso desses granitos, evidenciado pela presença de muscovita primária (Viana \& Pimentel 1994) sugere que a fonte magmática recebeu contribuição de rochas metassedimentares.

As idades U-Pb das rochas de Mara Rosa é semelhante às obtidas em rochas metavulcânicas e ortognaisses da região entre Piranhas e Sanclerlândia, oeste de Goiás. Nessa região, os protólitos ígneos calci-alcalinos dos gnaisses e metavulcânicas cristalizaram entre ca. 929 e $630 \mathrm{Ma}$ e foram metamorfizados entre ca. 630-600 Ma, como indicam as idades U-Pb de zircão e titanita (Pimentel et al. 1991 a). Composições isotópicas de $\mathrm{Sr}$ e $\mathrm{Nd}$ e elementos traço das rochas do oeste de Goiás são compatíveis com ambiente de arco intraoceânico.

As características isotópicas gerais de $\mathrm{Sm}-\mathrm{Nd}$ das rochas de Mara Rosa são também semelhantes às da região de Arenópolis, oeste de Goiás, com valores positivos de $\varepsilon_{\mathrm{Nd}}(\mathrm{T})$ e a maioria das idades modelo TDM mais jovens que 1,1 Ga (Fig. 6). O diagrama de evolução isotópica de $\mathrm{Nd}$ mostra, para efeito de comparação, o campo composicional de gnaisses arqueanos das regiões de Uva, Itapirapuã e da cidade de Goiás (Pimentel \& Fuck 1996, em preparação).

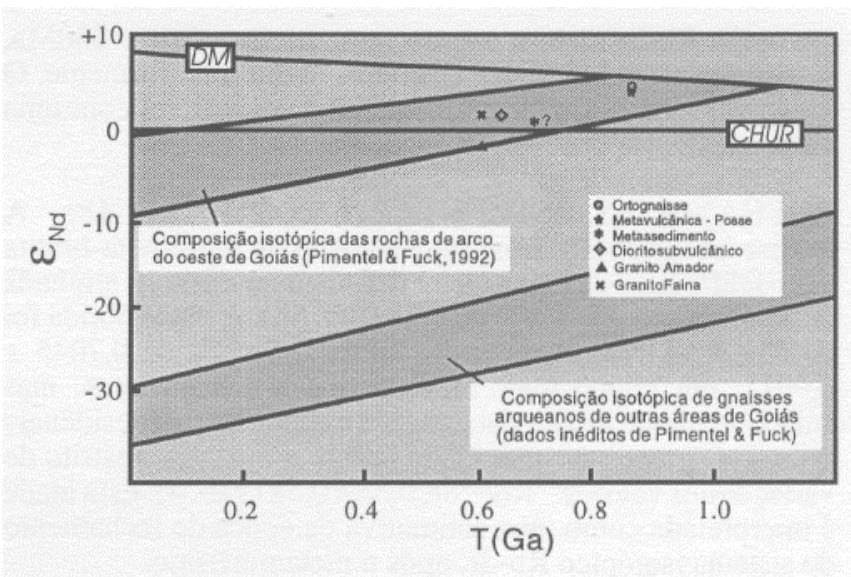

Figura 6 - Diagrama de evolução isotópica de $\mathrm{Nd}$. Figure 6 - Nd isotopic evolution diagram.

Os dados aqui apresentados revelam que terrenos de arco neoproterozóicos não ocorrem apenas na região ocidental de Goiás, mas também a cerca de $300 \mathrm{~km}$ ao norte, na região de Mara Rosa. A extensão desses terrenos juvenis mais a norte, para a porção centro-norte da Província Tocantins, também é possível, pois as unidades metavulcânicas e ortognáissicas similares às descritas em Mara Rosa e Arenópolis são conhecidas em vastas áreas na porção norte do Maciço de Goiás.

O evento de acreção crustal neoproterozóico é, portanto, de importância regional no desenvolvimento tectônico da Faixa Brasília e da Província Tocantins. Arcos-de-ilha intra-oceânicos se desenvolveram e provavelmente coalesceram em áreas oceânicas a oeste da margem ocidental (referência geográfica atual) do continente São Francisco-Congo entre ca. 900 e 640 Ma. Assim, durante esse período, é possível que este continente esteve marginado, a oeste, por um amplo oceano, eventualmente fechado durante a colisão entre os continentes São Francisco e Amazônico, durante a amalgamação do Gondwana Ocidental (Brito Neves \& Cordani 1991). Subducção de litosfera oceânica na costa oeste do continente São FranciscoCongo foi parcialmente contemporânea com o evento de fragmentação do supercontinente Rodinia, o que sugere que a Faixa Brasília ocupou uma posição periférica àquele supercontinente, compatível com as reconstruções continentais neoproterozóicas sugeridas por Hoffman (1991) e Dalziel (1991).

Agradecimentos À CIDA (Canadian International Development Agency) pelos recursos para as análises U-Pb. Aos corpos técnicos do CPGeo-USP pelas análises Rb-Sr, e do GEOTOP, Montreal, onde as análises U-Pb. Ao Conselho Nacional de Desenvolvimento Científico e Tecnológico $\mathrm{CNPq}$, pelos recursos financeiros. À Mineração Genipapo (WMC) pelo apoio logístico durante os trabalhos de campo.

\section{REFERENCIAS}

ALMEIDA, F.F.M. DE; HASUI, Y.; NEVES, B.B.DEB. \& FUCK, R.A. 1981, Brazilian structural provinces: an introduction. Earth Sci. Rev. 17:1-29.

ARANTES, D. OSBORNE,G.A. BUCK,P.S. \& PORTO, C.G. 1991. The Mara Rosa volcano-sedimentary sequence and associated gold mineralization, In: LADEIRA.E.A. (ed.) Brazil Gold'91, Balkema, Rotterdam, p.221-229.
ASMERON, Y JACOBSEN.S.B. KNOLL.A.H. BUTTERFIELD.N.J. \& SWETT.K. 1991. Strontium isotopic variation of Neoproterozoic seawater: implications for crustal evolution: Geochim. Cosmochim. Acta, 55:2883-2894.

BELL, R.T. \& JEFFERSON.C.W. 1987. A hypothesis for an AustralianCanadian connection in the late Proterozoic and the birth of the Pacific Ocean. In: PACIFIC RIM CONGRESS'87, Proceedings... Australian Inst. Mining Metall. Victoria, p. 39-50. 
BERNASCONI, A. 1983. The Archaean terranes of central eastern Brazil: a review. Precamb. Rex. 23:107-131.

BOND, G. NICKESON.B.A. \& KOMINZ.M.A. 1984. Break up of a supercontinent between 625 and $555 \mathrm{Ma}$ : new evidence and implications for continental histories. Earth Plan. Sci. Lett. 70: 325-345.

BRITO NEVES, B.B. DE \& CORDANI, U.G. 1991. Tectonic Evolution of

South America during the Late Proterozoic. Precamb. Res. 53:23-40

BROWN, G.C. 1982. Calc-alkaline intrusive rocks: their diversity, evolution and relation to volcanic arcs. In: THORPE, R.S. (ed.) Andesites, orogenic andesites and related rocks. N. York, J. Wiley, p. 437-461.

CHAPPELL, B.W. 1984. Source rocks of I- and S-type granites in the Lachlan Fold Belt, southeastern Australia. Philos. Trans. R. Soc. London, A310:693-707.

CULLERS, R.L. \& GRAF, J.L. 1984. Rare Earth Elements in igneous rocks of the continental crust: intermediate and silicic rocks - ore petrogenesis. In: HENDERSON, P. (ed.) Rare Earth Element Geochemistry. Elsevier, N. York, 275-316.

DALZD3L, I.W.D. 1991. Pacific margins of Laurentia and East AntarcticaAustralia as a conjugate rift pair: evidence and implications for an Eocambrian supereontinent: Geology, 19:598-601.

DALZffiL, I.W.D. 1992. On the organization of American plates in the Neoproterozoic and the breakout of Laurentia: GSA Today, 2(11):237-241.

DALZffiL, I.W.D. 1995. Earth before Pangea. Sclent. Am. Jan, p.58-63,

DANNI, J.C.M. FUCK.R.A. \& LEONARDOS.O.H. 1982. Archean and Lower Proterozoic Units in central Brazil. Geol. Rundschau, 71(1):291-317.

DERRY, L.A. KAUFMAN.A.J. \& JACOBSEN.S.B. 1992. Sedimentary cycling and environmental change in the Late Proterozoic: evidence from stable and radiogenic isotopes:" Geochim. Cosmochim. Acta 56:1317-1329

DRAKE JR. A.A. 1980. The Serra de Caldas Window, Goiás. U.S.G.S. Prof. Paper 1119/A-B:1-11.

FERREIRA FILHO, C.F. KAMO.S.L. FUCK.R.A. KROGH.T.E. \& NALDRETT.A.J. 1994. Zircon and rutile U-Pb geochronology of the Niquelândia mafic-ultramafic intrusion, Brazil: constraints for the timing of magmatism and high-grade metamorphism: Precamb. Res. 68:241-255.

FUCK, R.A. PIMENTEL.M.M. \& BOTELHO,N.F. 1987. Granitoid rocks in western-central Brazil-a review, In: INTERN. SYMP. GRANITES AND ASSOC. MINERAL, ISGAM, Salvador, Brazil, Ext. Abstr.. SRGM-BA, pp.53-59.

FUCK, R.A. PIMENTEL.M.M. \& SILVAJLJ.H.D. 1994. Compartimentação tectônica da porção oriental da Província Tocantins. In: CONGR. BRAS. GEOL. 38. Camboriú, Brasil, Res. Expand... SBG, v.1, pp.215-216.

HASUI, Y. \& ALMEIDA.F.F.M. DE 1970. Geocronologia do centro-oeste brasileiro. Boi. Soc. Bras. Geol. 19:5-26.

HASUI, Y. COSTA.J.B.S. \& HARALYI.N.L.E. 1994. Estrutura em quilha Brasil Central, uma feição fundamental na geologia de Goiás e Tocantins. Geociências, 13(2):463-497.

HOFFMAN, P.F. 1991. Did the breakout of Laurentia turn Gondwanaland inside out? Science, 252:1409-1412.

IANHEZ, A.C. SIMÕES.M.A. LUZ.O.S. 1984. Grupo Dois Irmãos e Amorinópolis - duas novas seqüências vulcano-sedimentares no sudoeste de Goiás, In: CONGR. BRAS. GEOL. 33. Anais... SBG, Rio de Janeiro, pp.2577-2589.

KNOLL, A.H. 1992. The early evolution of eukaryotes: a geological perspective. Science, 256:622-627.

KROGH, T.E. 1973. A low-contamination method for hydrothermal decomposition of zircon and extraction of $\mathrm{U}$ and $\mathrm{Pb}$ for isotopic age determinations. Geochim. Cosmochim. Acta, 37:485-494.

KROGH, T.E. 1982. Improved accuracy of U-Pb zircon ages by the creation of more concordant systems using an air abrasion technique. Geochim. Cosmochim. Acta, 46:637-649.

KUYUMJIAN, R.M. 1989. Geoquímica e significado do posicionamento geotectônico de rochas plutônicas da região de Chapada, Goiás, Brasil In: CONG. BRAS. GEOQ. 2. Anais... SBGq-CPRM/DNPM, Rio de Janeiro, pp. 195-201.

LACERDA, H. 1986. As mineralizações auríferas da região de Mara Rosa (GO). Rev. Bras. Geoc. 16(3):274-284.

MACHADO, E.C. 1981. Novas considerações e integração geológica na região de Pilar-Crixás/Mara Rosa-Porangatu. In: SIMP. GEOL. CENTRO-OESTE, 1. Goiânia, Ata... Soc. Brás. Geologia, pp.300-318.
MOORES, E.M. 1991. Southwest U.S.-East Antarctica (SWEAT) connection: a hypothesis. Geology, 19:425-428.

MOORES, E.M. 1993. Neoproterozoic oceanic crustal thinning, emergence of continents, and origin of the Phanerozoic ecosystem: a model. Geology, 21:5-8.

PIMENTEL, M.M. 1991. Late Proterozoic Crustal Evolution of the Tocantins Province in central Brazil: an Isotopic and Geochemical Study. 248 p. (PhD Thesis, University of Oxford).

PIMENTEL, M.M. \& FUCK.R.A. 1992. Neoproterozoic crustal accretion in central Brazil. Geology, 20:375-379.

PIMENTEL, M.M. \& FUCK.R.A. 1993. Geocronologia Rb-Sr da porção sudoeste do Maciço de Goiás. Rev. Bras. Geoc. 23(2): 1-8.

PIMENTEL, M.M. HEAMAN.L. \& FUCK.R.A. 1991a. U-Pb zircon and sphene geochronology of late Proterozoic volcanic arc rock units from southwestern Goiás, central Brazil: J South Am. Earth Sci. 4:329-339.

PIMENTEL, M.M. HEAMANJL. \& FUCK.R.A. 1992. Idade do meta-riolito da seqüência Maratá, Grupo Araxá, Goiás: estudo geocronológico pelos métodos U-Pb em zircões, Rb-Sr e Sm-Nd. Anais Acad. Brás. Ciên. 64:19-28.

PIMENTEL, M.M. HEAMAN.L. FUCK.R.A. \& MARINI, O.J. 1991b. U-Pb zircon geochronology of Precambrian tin-bearing continental-type acid magmatism in central Brazil. Precamb. Res. 52:321-335.

PITCHER, W.S. 1983. Granite type and tectonic environment. In: HSU, K. (ed.) Mountain Building Processes. Acad. Press. London, 19-40.

REIS NETO, J.M. 1983. Evolução Geotectônica da Bacia do Alto Tocantins, Goiás. Dissertação de Mestrado, USP, 98p.

RIBEIRO FILHO, W. 1981. Reavaliação da geologia de Pilar-Mara Rosa, In: SIMP. GEOL. CENTRO- OESTE.1. Goiânia, Brazil, Atas... SBG, v.1,pp.281-296.

RICHARDSON, S.V. JONESJ.P \& KESSLER.S.E. 1988. Strontium isotopic geochemistry of Pan-African/ Brasíliano rocks, Chapada copper deposit. Econ. Geol. 81:1884-1898.

RODRIGUES J.B. \& PIMENTEL.M.M. 1995. Caracteris-ticas geoquimicas e isotópicas de rochas granitóides e metavulcânicas da região de Iporá, Goiás. In: SIMP. GEOL. CENTRO-OESTE, 5, Anais...Goiânia, SBGNCO,p.123-126

STEIGER, R.H. \& JÀGER, E. 1977. Subcommision on geochronology: convention on the use of decay constants in geo- and cosmochronology. Earth Planet. Sci. Lett. 36:359-362.

STAGEY, J.S. \& KRAMERS, J.D. 1975. Approximation of terrestrial lead isotope evolution by a two-stage model. Earth Plan. Sci. Lett. 6:15-25.

STRIEDER, A.J. \& NILSON.A.A. 1992. Estudo petrológico de alguns fragmentos tectônicos da melange ofiolítica em Abadiânia (GO): 1 - O protólito dos corpos de serpentinito. Rev. Bras. Geoc. 22(3):338-352.

SUITA, M.T.F. KAMO.S.L. KROGH.T.E. FYFE.W.S. \& HARTMANN.L.A. 1994. U-Pb ages from the high-grade Barro Alto maficultramafic complex (Goiás, central Brazil):middle Proterozoic continental mafic magmatism and Upper Proterozoic continental collision. In: INTERN. CONFER. ON GEOCHR. COSMOCHR. AND ISOT. GEOL. 8. Berkeley, Abstracts... USGS Circular 1107, p.309.

TASSINARI, C.C.G. SIGA JR.O. \& TEIXEIRA.W. 1981. Panorama geocronológico do centro-oeste brasileiro: soluções, problemática e sugestões, In: SIMP. GEOL. CENTRO-OESTE, 1. Goiânia, Brasil, Atos.. SBG,v.1,pp.93-116.

VIANA, M.G. 1995. Geocronologia e geoquímica das rochas ortognáissicas e metavulcânicas da região de Mara Rosa, norte de Goiás. Dissertação de Mestrado, Univ. Brasília, 118p.

VIANA, M.G. \& PIMENTEL.M.M. 1994. Dados geoquímicos e isotópicos Sm-Nd preliminares para rochas metavulcânicas e metaplutônicas da região de Mara Rosa. In: SIMP. GEOL. CENTRO-OESTE, 4. Brasília, Anais... SBG, pp. 148-151.

YOUNG, G. 1995. Are Neoproterozoic glacial deposits preserved on the margins of Laurentia related to the fragmentation of two supercontinents? Geology, 23(2):97-192.

WHITE, A.J.R. 1979. Sources of granite magmas. Geol. Soc. Am. Abstr. Progr. 11:539.

Manuscrito A841

Recebido em 20 de Janeiro de 1996

Revisão do autor em 11 de junho de 1996

Revisão aceita em 17 de junho de 1996 